\title{
Evaluation of air gap membrane distillation process running under sub- atmospheric conditions: Experimental and simulation studies
}

\author{
Ahmad S. Alsaadi, Lijo Francis, Husnul Maab, Gary L. Amy, Noreddine Ghaffour \\ Water Desalination and Reuse Center, King Abdullah University of Science and Technology (KAUST), 23955-6900 \\ Thuwal, Saudi Arabia, Tel. +966-28082180,Email: noreddine.ghaffour@kaust.edu.sa
}

\begin{abstract}
The importance of removing non-condensable gases from air gap membrane distillation (AGMD) modules in improving the water vapor flux is presented in this paper. Additionally, a previously developed AGMD mathematical model is used to predict to the degree of flux enhancement under sub-atmospheric pressure conditions. Since the mathematical model prediction is expected to be very sensitive to membrane distillation (MD) membrane resistance when the mass diffusion resistance is eliminated, the permeability of the membrane was carefully measured with two different methods (gas permeance test and vacuum MD permeability test). The mathematical model prediction was found to highly agree with the experimental data, which showed that the removal of non-condensable gases increased the flux by more than three-fold when the gap pressure was maintained at the saturation pressure of the feed temperature. The importance of staging the sub-atmospheric AGMD process and how this could give better control over the gap pressure as the feed temperature decreases are also highlighted in this paper. The effect of staging on the sub-atmospheric AGMD flux and its relation to membrane capital cost are briefly discussed.
\end{abstract}

Keywords: Membrane distillation (MD); Air gap width; Heat and mass transfer coefficients; Sub-atmospheric pressure; Gas permeance.

\section{Introduction}

Air gap membrane distillation (AGMD) is one of the four common configurations that became the first choice for pilot testing [1-7]. However, this configuration still suffers from producing low flux compared to direct contact membrane distillation (DCMD) or vacuum membrane 
distillation (VMD) configurations [8-10]. We have demonstrated in our previous work [11] that heat recovery is very essential for enhancing the thermal efficiency of the AGMD process. But, the increase in thermal efficiency does not come free and the recovered heat always results in lowering the distillate production rate through the reduction of the driving force across the membrane. This makes improving the AGMD flux at large scale very challenging. One good approach toward solving the low flux problem is to study some of the techniques that are applied in the conventional thermal-based desalination processes which have been proved over many years of operational experience to be very effective in enhancing the water vapor flux in order to adapt them for the AGMD process. Multi-Stage Flash (MSF) is one of these conventional thermal desalination technologies that shares some similarity with the AGMD configuration. In MSF process, non-condensable gases are removed from the distillation chambers through steam ejectors and the seawater feed is de-aerated before it enters the distillers. Moreover, the condenser tube bundles inside the distillers are separated from the brine pool by more than 2 meters (to avoid salt carryover along with the rising vapor) without any adverse effect on the production capacity (flux). The hypothesis of such design is that as long as non-condensable gases are removed from distillers, the diffusion mass transfer resistance is negligible and the distance between the evaporation and condensation surfaces is not that important. Even though MSF is operated under small $\Delta \mathrm{T}\left(5-10^{\circ} \mathrm{C}\right)$ and has a gap of more than 2 meter between the evaporation and condensation surfaces, the process flux reaches more than $800 \mathrm{~kg} / \mathrm{m}^{2} . \mathrm{hr}$ [12-13]. As its name may suggest, each train of MSF is consisted of 18-24 stages in series to maintain the vacuum pressure inside each stage at saturation pressure of the feed that enters that specific stage.

AGMD, in contrast, introduces a thin layer of ambient air $(2-10 \mathrm{~mm})$ between the MD membrane and the condensation surface as a thermal insulation layer to minimize heat loss by conduction. However, the non-condensable gases in this thin layer have been reported in several AGMD studies to be the dominating mass transfer resistance of the process [14-17]. The vapor formed at the interface of the hot side of the membrane must diffuse all the way through the pores of the membrane and across the air gap before it condenses on the cold surface (Figure1).

According to Fick's law, "the diffusive mass transfer is inversely proportional to the diffusion path". Jonsson's et al. [18] theoretical work and Kimura's et al. [19] experimental study demonstrated that AGMD water vapor flux decreases as the air gap thickness increases. 
In other studies, Gostoli et al. [20] tested flat sheet membranes in air gap modules under different sub- atmospheric pressures and found that the flux increases as the absolute pressure of the gap pressure decreases. Similarly, Guijt et al. [21] removed the non-condensable gases from their air gap hollow fiber module and observed that the flux increased by three folds. Furthermore, the studies of steam condensers have well demonstrated that non-condensable gases shift the transport mechanism of the condensation process from being liquid-phase heat transfer controlled to a vapor-phase mass transfer controlled [22].

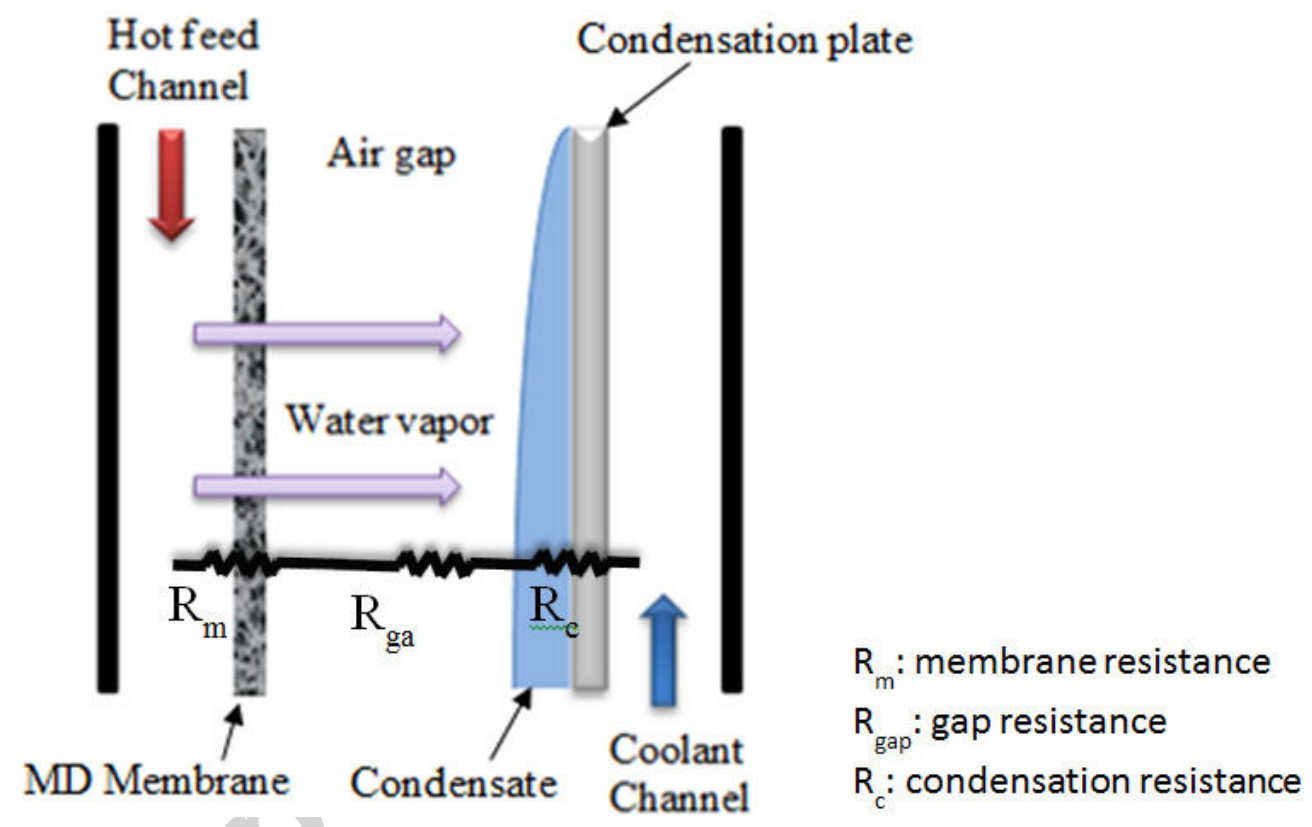

Figure 1: Mass transfer resistance across the air gap in a vertical flat sheet module.

The presence of the non-condensable gasses not only affects the mass transfer but also impair the heat transfer as well. When a vapor containing non-condensing gases condenses on a cold surface, the concentration of the gases in the immediate vicinity of the surface becomes greater than that in the bulk air-vapor mixture due to the low solubility of these gases in the liquid condensate. As a result, the partial pressure, and hence the temperature of the vapor near the surface, is reduced. This, in turn, reduces the temperature difference across the condensate film, and thereby reduces the heat flux. For instance, the studies on the effect of non-condensable gases on film type condensation on a flat vertical plate and in the absence of forced convection (i.e., under natural convection conditions), have indicated that a gas mass fraction as little as 0.5 
$\%$ can cause a reduction of about $50 \%$ in heat flux [23]. Therefore, the enhanced water vapor transfer can only be seen near the saturation pressure of the hot liquid phase, which is the optimal operating condition of the MSF process.

In all thermal separation processes, the heat and mass transfer rates are always coupled and the rate at which a component is being separated from a mixture must be limited by either its heat transfer mechanism or its mass transfer mechanism. At low mass transfer resistance, the thermal separation process becomes heat transfer limited and the opposite is true when the heat transfer resistance is lower. Thus, the high mass transfer rate makes MSF a heat transfer limited process and one can infer this fact from the typical MSF design that allocates more than 60 folds of the evaporation surface area for condensation [12-13]. All the experimental findings mentioned earlier support the idea of adapting the removal of non-condensable gases applied in MSF technology for AGMD, which practically requires staging the process in series in order to maintain the feed temperature at the saturation pressure. The adaption of this technique may allow us here to refer to this technology as sub-atmospheric AGMD.

Since Guijt et al., [21], Gostoli et al., [20] and Prince et al., [24] are the only works reported for the removal of non-condensable gases and the concept of staging sub-atmospheric AGMD has not been introduced in MD literature, we believe that there is still a knowledge gap in the MD literature in this regard and the work of this paper tries to close part of it. Additionally, there is a potential enhancement in the water vapor flux of AGMD if it is operated at sub-atmospheric pressure. Therefore, this paper reports experimental and simulated fluxes predicted by our previously reported AGMD mathematical model [11] running under sub-atmospheric pressure and compare them to each other. The experiments and simulated scenarios have been conducted at different feed temperatures and different sub-atmospheric pressures using three different gap widths $(5,11$, and $21 \mathrm{~mm})$. The effect of the coolant temperature and staging sub-atmospheric AGMD process on water vapor flux are also discussed.

\section{Theory}

It was highlighted in previous work [11] that the mass transfer resistance across the AGMD membrane can be described as two resistances in series according to the following equation:

$$
R_{v}=R_{m v}+R_{k v}
$$


where $R_{m v}$ is the mass transfer resistance exerted by all non-condensable gases within the membrane pores on the water vapor molecules, and $\mathrm{R}_{\mathrm{kv}}$ is the mass transfer resistance due to the momentum loss during the collision of water vapor molecules with the internal walls of the membrane pores. In a flux form, the above equation can be written as:

$$
\frac{1}{J_{m}}=\frac{1}{J_{m v}}+\frac{1}{J_{k v}}
$$

where $\mathrm{J}_{\mathrm{m}}$ is the total flux across the membrane, $\mathrm{J}_{\mathrm{mv}}$ and $\mathrm{J}_{\mathrm{kv}}$ are the water vapor fluxes due to molecular diffusion and Knudsen diffusion, respectively. The Knudsen $\left(\mathrm{J}_{\mathrm{k}}\right)$ and molecular diffusion $\left(\mathrm{J}_{\mathrm{mv}}\right)$ fluxes are calculated by the following equations [11]:

$$
\begin{gathered}
J_{k v}=\frac{4}{3} \frac{d \varepsilon}{b \tau} \sqrt{\frac{M_{v}}{2 \pi R T}}\left(P_{h m}-P_{m a}\right) \\
J_{m v}=\frac{M_{v}}{1-y} \frac{\varepsilon D_{A B}}{\tau b R T}\left(P_{h m}-P_{m a}\right)
\end{gathered}
$$

where $\mathrm{d}, \mathrm{b}, \tau$, and $\varepsilon$ are the average diameter of pores, the membrane thickness, the tortuosity of the pores and the porosity of the membrane, respectively, $M_{v}$ is the molecular weight of water, $R$ is the universal gas constant, $\mathrm{D}_{\mathrm{AB}}$ is the mass diffusivity coefficient between air and water vapor, $\mathrm{y}$ is the mole fraction of water vapor in the membrane pores, $\mathrm{T}$ is the average temperature inside the membrane pores, and $\mathrm{P}_{\mathrm{hm}}$ and $\mathrm{P}_{\mathrm{ma}}$ are the water vapor pressures at the membrane interface of the feed and air gap sides, respectively.

The mass transfer across the air gap is only controlled by the molecular diffusion mechanism and can be combined also with the membrane resistance in series according to the following equation:

$$
\frac{1}{\mathrm{~J}_{\mathrm{AGMD}}}=\frac{1}{\mathrm{~J}_{\mathrm{m}}}+\frac{1}{\mathrm{Jgap}_{\text {gap }}}
$$

At high partial pressure of non-condensable gases, which is the typical case of an atmospheric AGMD, the mass transfer is mainly controlled by the molecular diffusion mechanism and the micro porous membrane structure resistance is negligible. Such a fact is supported by our experimental and mathematical model findings [25] as well as by Alkhudhiri et al. [26] and Kimura et al. [19] works that showed that changing the membrane pore size from 0.2 $\mu \mathrm{m}$ to $0.45 \mu \mathrm{m}$ did not significantly increase the water vapor flux. However, when the gap is 
completely evacuated from the non-condensable gases then the diffusive mass transfer mechanism disappears. The controlling resistance should shift somewhere else; either to the membrane structure resistance or to one of the heat transfer coefficients of the process fluids. In this case, an accurate measurement of the membrane mass transfer coefficient becomes very essential for developing an accurate mathematical model. Schofield et al. [27] highlighted that the calculation of the membrane mass transfer coefficient from the measurement of the membrane average pore size, porosity and the estimation of membrane tortuosity is not accurate enough. Thus, they developed semi-experimental procedure to calculate the membrane mass transfer coefficient. In this paper, the mass transfer coefficients of the membranes were carefully measured by two different methods. The first method was based on the gas permeance test [6] while the second one was based on a simple vacuum membrane distillation (VMD) test [28-29]. The details of both methods are presented in the experimental section below.

\section{Experiments}

\subsection{Membrane gas permeance test}

Two commercially available hydrophobic micro-porous non-woven supported polytetrafluoroethylene (PTFE) membranes (M1 and M2) with an average pore size of $0.2 \mu \mathrm{m}$ were subjected to $\mathrm{N}_{2}$ gas permeance tests. The permeability test was conducted with a commercial porometer device called Porolux 1000 (Germany). The sample holder diameter of the porometer is $18.5 \mathrm{~mm}$ and the pressure difference applied across the membranes spanned a range of 0 to 1 bar in 100 step-changes in the upstream pressure.

\subsection{VMD membrane permeability test}

Membrane specimens of $5 \mathrm{~cm}$ x $10 \mathrm{~cm}$ size were tested in a thermally insulated VMD flat sheet module made of poly methyl methacrylate, locally designed and fabricated [30]. The channel height was $2 \mathrm{~mm}$ for both feed and permeates sides. The membrane module was mounted vertically in a bench scale set up. The permeate vapor was condensed inside a $60 \mathrm{~cm}$ long glass coil immersed in an ice bath and collected in a sealed tank placed on an electronic Mettler Toledo balance (ML3002E Precision Balance, with an accuracy of $0.01 \mathrm{~g}$ ). The permeate weight, pressure and temperature of the water vapor that comes out of the VMD module were monitored 
using inline temperature and pressure sensors. The data was logged every 60 seconds via data acquisition software (Labview) to a computer hard drive. $2 \mathrm{~L} / \mathrm{min}$ deionized water at $70{ }^{\circ} \mathrm{C}$ was used as a feed solution. The temperature of the feed was monitored via in-line Pt100 sensors inserted at the entrance of the membrane module to give feedback signal to the heater controller. The vacuum is applied through a vacuum pump connected to the top of the permeate collection tank. The vacuum pressures at the initial time of all VMD runs were always lower than the saturation pressure of the hot feed. After reaching the maximum possible vacuum, the VMD setup was isolated to prevent any water vapor loss through the vacuum line. The VMD process is considered a semi-closed process and the accumulation of the distillate inside the tank and maybe small air leak caused the absolute pressure of the system to increase at a rate of about $0.05 \mathrm{kPa} / \mathrm{min}$.

\subsection{Sub-atmospheric AGMD experimental setup}

Membrane specimens of $5 \mathrm{~cm}$ x $10 \mathrm{~cm}$ size were tested in an AGMD flat sheet module made of polymethyl meth-acrylate (Figure 2a) locally designed and fabricated [31]. The channel height was $2 \mathrm{~mm}$ for both feed and permeates sides. The membrane module was mounted vertically in a bench scale set up. After it is condensed on a $0.25 \mathrm{~mm}$ thick stainless steel sheet, the permeate is collected from the bottom of the module in well-sealed stainless steel tank placed on an electronic Mettler Toledo balance (ML3002E Precision Balance, with an accuracy of $0.01 \mathrm{~g}$ ). The air gap width was varied by using different thicknesses of polymethyl methacrylate frames inserted between the membrane and the condensation plate $(5 \mathrm{~mm}, 11 \mathrm{~mm}, 16 \mathrm{~mm}$ and $21 \mathrm{~mm})$. Starting at a pressure below the saturation pressure of the hot feed, the absolute pressure inside the air gap was allowed to increase over time at an approximate rate of $0.06 \mathrm{kPa}$ per minute. The change in the permeate weight was logged every 60 seconds via data acquisition software (Labview) to a computer hard drive. Red Sea water was used as feed solutions, while deionized water was used as coolant. Feed and coolant temperatures were monitored by in-line Pt100 sensors inserted at the entrance of the membrane module, and were used to control the heater and chiller temperatures via feedback control to the chiller and heater. A schematic diagram of the AGMD experimental setup and the sub-atmospheric AGMD module are shown in Figure 2. 

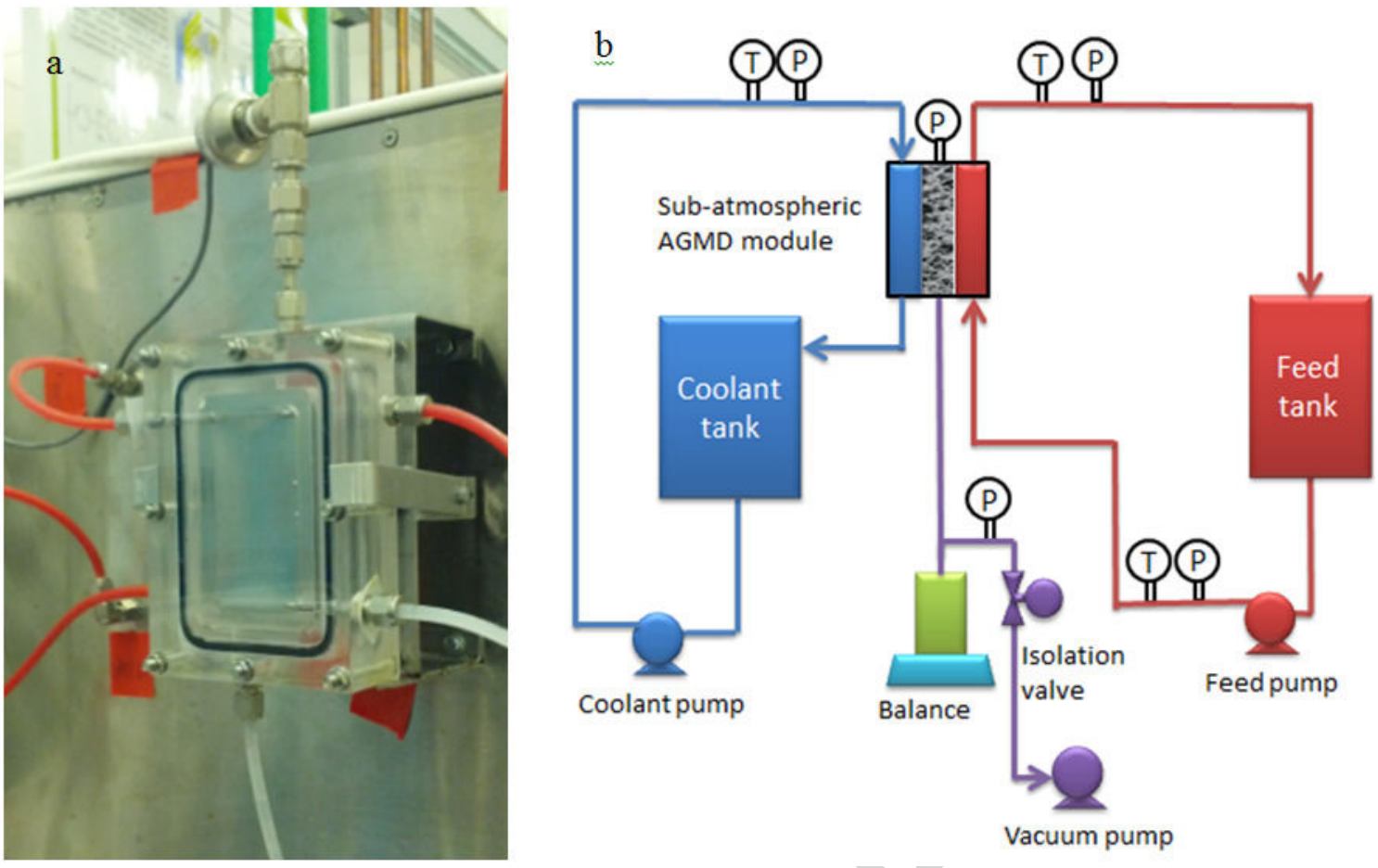

Figure 2: (a) Flat sheet sub-atmospheric AGMD module, (b) A schematic diagram of the subatmospheric AGMD experimental setup.

\subsection{Mathematical model validation procedure}

The validation procedure was based on comparing the predicted mass flux to the measured one.

Thus, a matrix of experimental runs (Table 1) was used to map representative operating conditions of the sub-atmospheric AGMD process.

Table 1: Detailed conditions of the bench scale tests used in validating the model .

\begin{tabular}{|c|c|c|c|c|}
\hline$\sqrt{2}$ & $\begin{array}{l}\text { Membrane } \\
\text { type }\end{array}$ & $\begin{array}{l}\text { Air gap width } \\
(\mathrm{mm})\end{array}$ & $\begin{array}{l}\text { Feed temp. ( } \\
\left.{ }^{\circ} \mathrm{C}\right)\end{array}$ & Coolant temp. $\left({ }^{\circ} \mathrm{C}\right)$ \\
\hline Repeatability test & M1 & 11 & 80 & 20 \\
\hline Different membranes & M1, M2 & 11 & 80 & 20 \\
\hline Different air gaps & M1 & $6,11,21$ & 60 & 20 \\
\hline Different feed temps & M1 & 11 & $60,70,80$ & 20 \\
\hline Different coolant temps & M1 & 11 & 80 & 10,20 \\
\hline Other conditions & \multicolumn{4}{|c|}{$\begin{array}{l}\text { All tests have been conducted with Red Sea water as feed and deionized } \\
\text { water as coolant at equal flow rates of } 1.5 \mathrm{~L} / \mathrm{min} \text { in counter current flow } \\
\text { regime }\end{array}$} \\
\hline
\end{tabular}




\section{Results and discussion}

\subsection{Membrane gas permeance test}

The porometer reported the nitrogen volumetric flow rates at standard conditions. Therefore, the sample holder surface area and the water molecular weight were incorporated with the ideal gas law at standard conditions to convert the nitrogen volumetric flow rates into water vapor mass flux (Figure 3) according to following equation:

$$
J=\frac{M V P_{0}}{R T_{0} A}
$$

where $P_{o}$ and $T_{o}$ are the pressure and temperature at standard conditions, respectively, $v$ is the nitrogen volumetric flow rate, and $\mathrm{A}$ is the sample holder surface area.

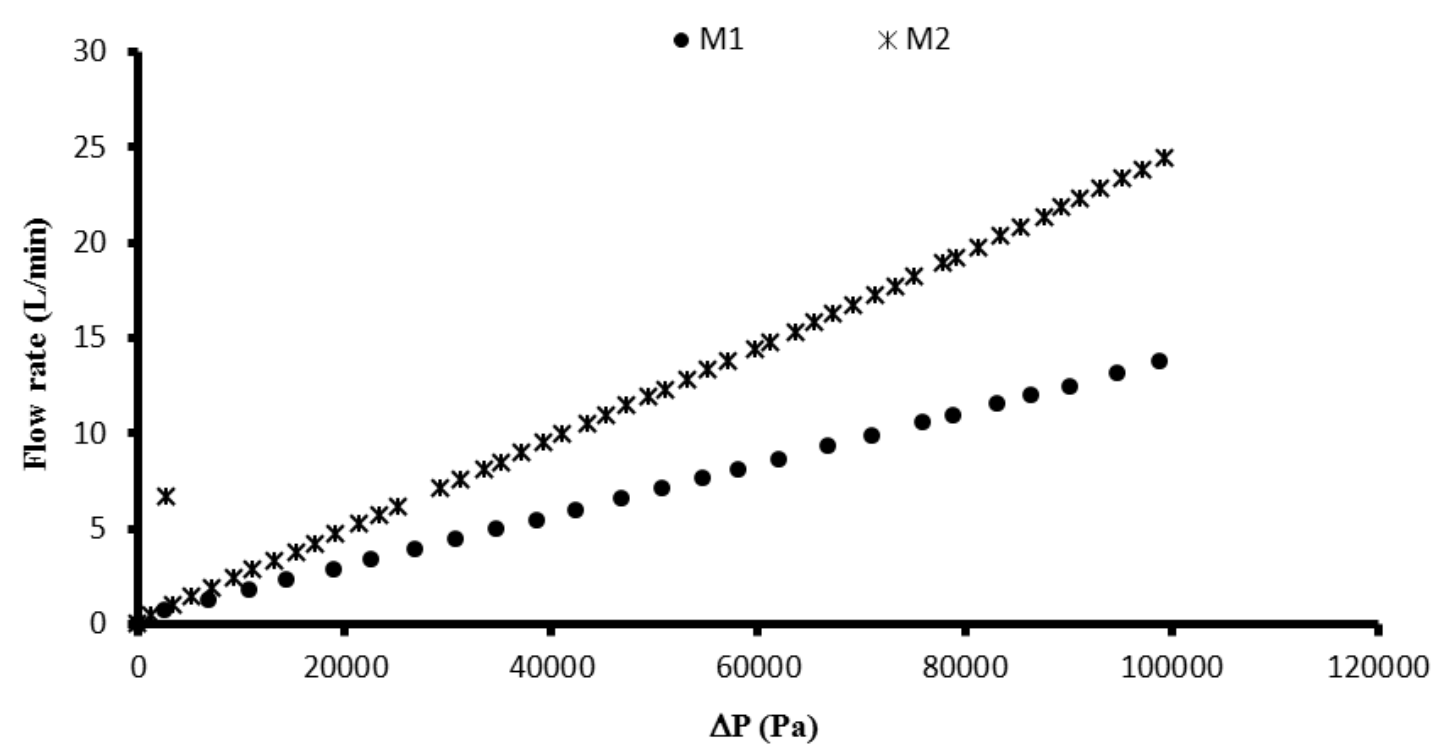

Figure 3: Gas permeance tests $v s \Delta \mathrm{P}$ for the two PTFE membranes.

The flux represented in Figure 4 is at least one order of magnitude higher than the expected flux of the MD process. The most probable explanation for such result is the different conditions at which the gas permeance test and the MD process are conducted. To be more specific, the gas density and viscosity under the gas permeance test condition are much more important than when they are under the MD process conditions. To prove such explanation, we started from the mass transfer mechanism of the gas permeance test which is expected to be dominated by the viscous flow regime described by the following equation: 


$$
J_{P}=0.125 \frac{r^{2} \epsilon}{\tau b}\left(\frac{M P_{a v g}}{\eta R T}\right) \Delta \mathrm{P}
$$

where $r$ is the average pores radius, $\eta$ is the water vapor viscosity, $P_{a v g}$ is the average pressure inside the membrane pores, and $\Delta \mathrm{P}$ is the pressure drop across the membrane.

- M1 $\quad * M 2$

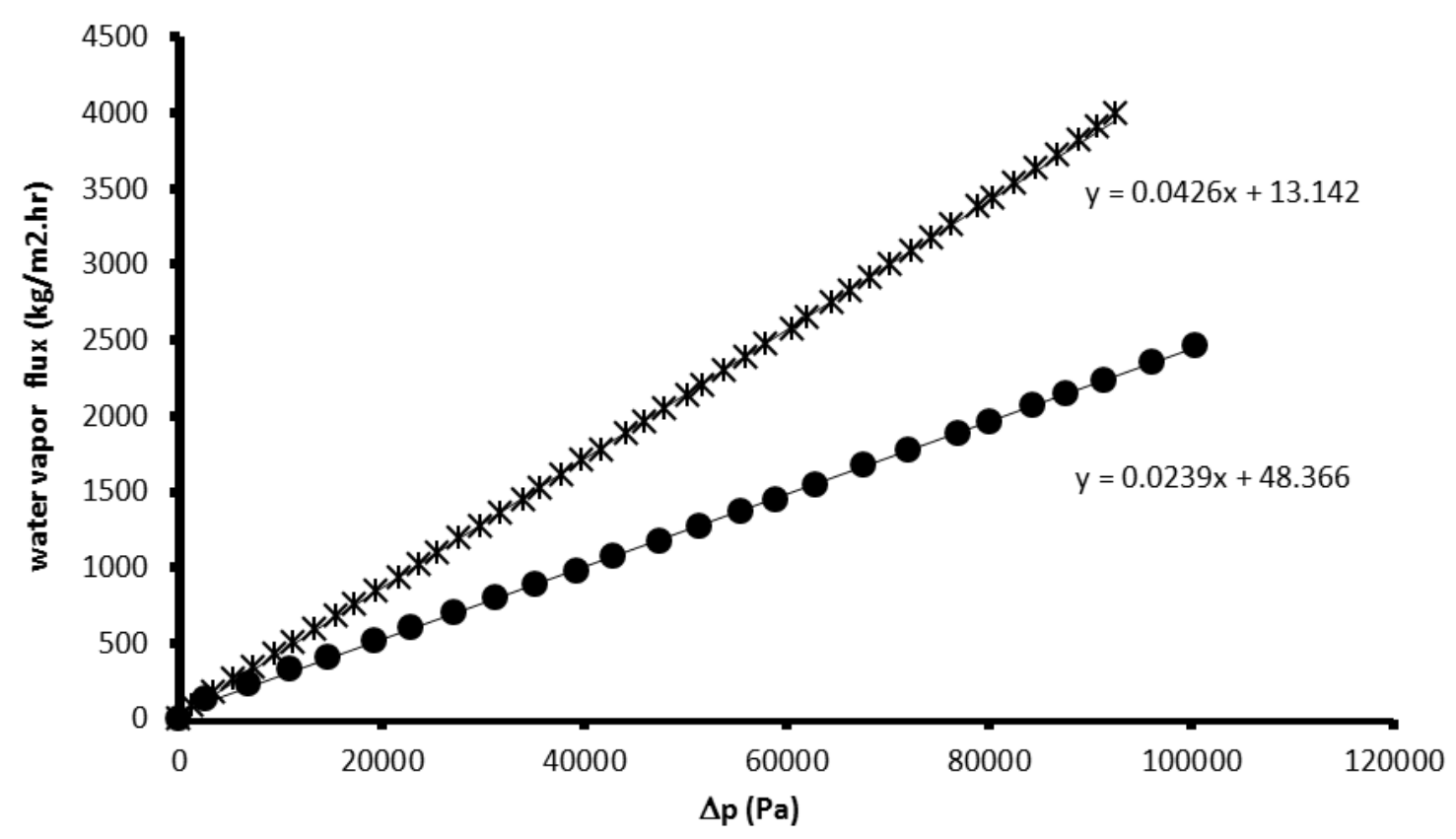

Figure 4: Water vapor flux vs $\Delta \mathrm{P}$ calculated under the gas permeance conditions.

Since the gas density can be computed from the ideal gas law as:

$$
\rho=\frac{M P_{\text {avg }}}{R T}
$$

Thus, the viscous flow regime can be rewritten as:

$$
J_{P}=0.125 \frac{r^{2} \epsilon}{\tau b}\left(\frac{\rho}{\eta}\right) \Delta \mathrm{P}
$$

Eq. (9) shows clearly that the mass flux is a function of the density and viscosity of the gas while under the sub-atmospheric AGMD and VMD conditions the mass transfer is expected to be dominated by Knudsen flow regime as mentioned in Section 2. Knudsen flow regime is only a function of the driving force across the membrane if we neglect the small effect of the change in temperature inside the membrane pores. Therefore, if we factor out the effect of density and viscosity of the gas permeance test through normalizing the flux for density and viscosity, then we would expect the flux of the gas permeance test to be comparable to the MD flux. Now, if we 
plot the normalized flux of each membrane against $\Delta \mathrm{P}$, as it is shown in Figure 5, we will find that the mass transfer coefficients (the slop) obtained for each membrane are almost the same as those obtained by the VMD method, which we are going to discuss in the next section.

The mass transfer coefficient of M2 was found to be $40 \%$ higher than M1 value (Table 2) and both coefficients values are of the same order of magnitude as those reported in MD literature.

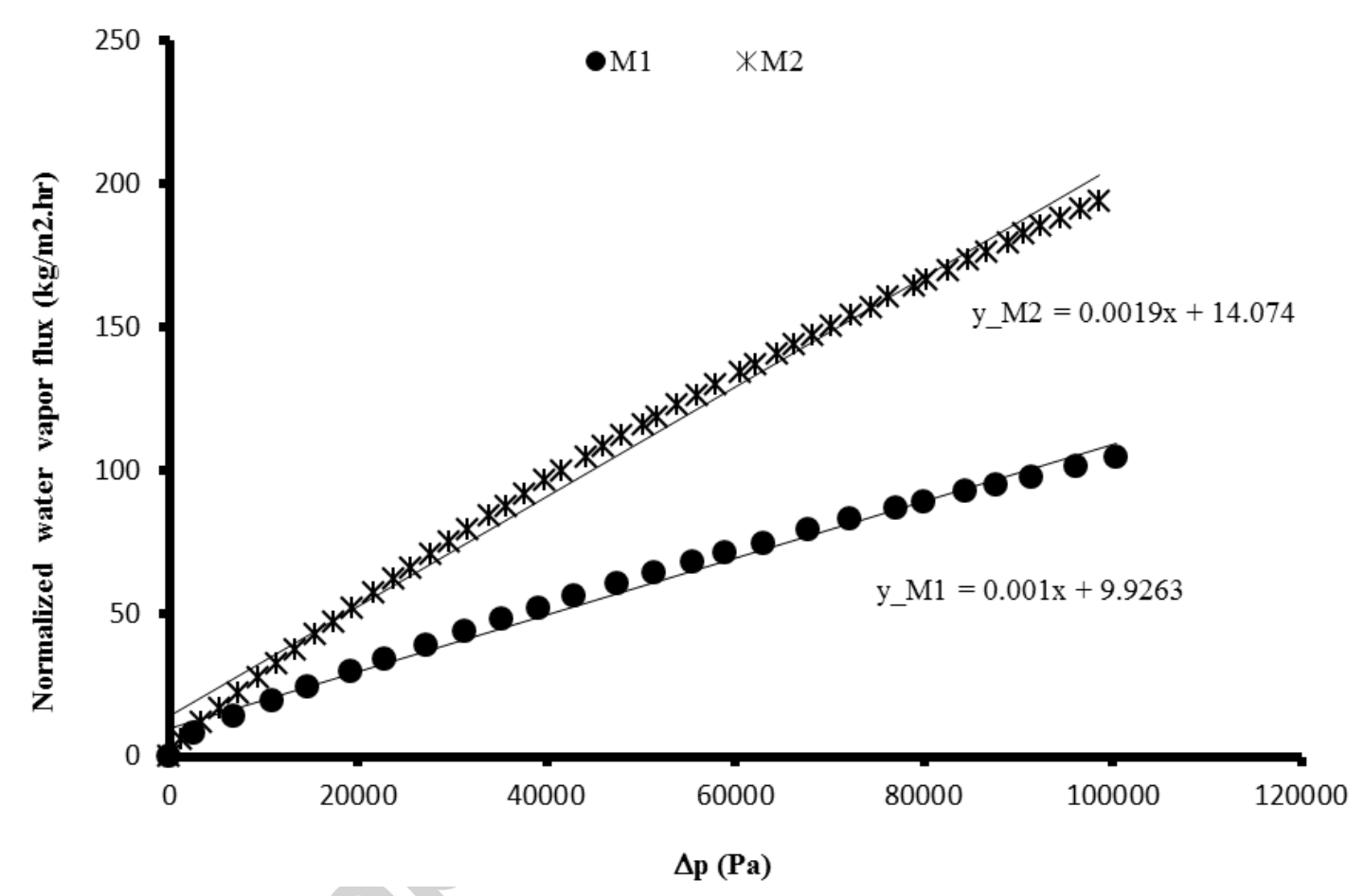

Figure 5: Normalized water vapor flux for density and viscosity $v s \Delta \mathrm{P}$ (data obtained from the gas permeance test).

\subsection{VMD membrane permeability test}

The change over time of water vapor flux and the absolute pressure of the permeate side of the VMD permeability test is shown in Figures 6 and 7, for M1 and M2 membranes, respectively. 


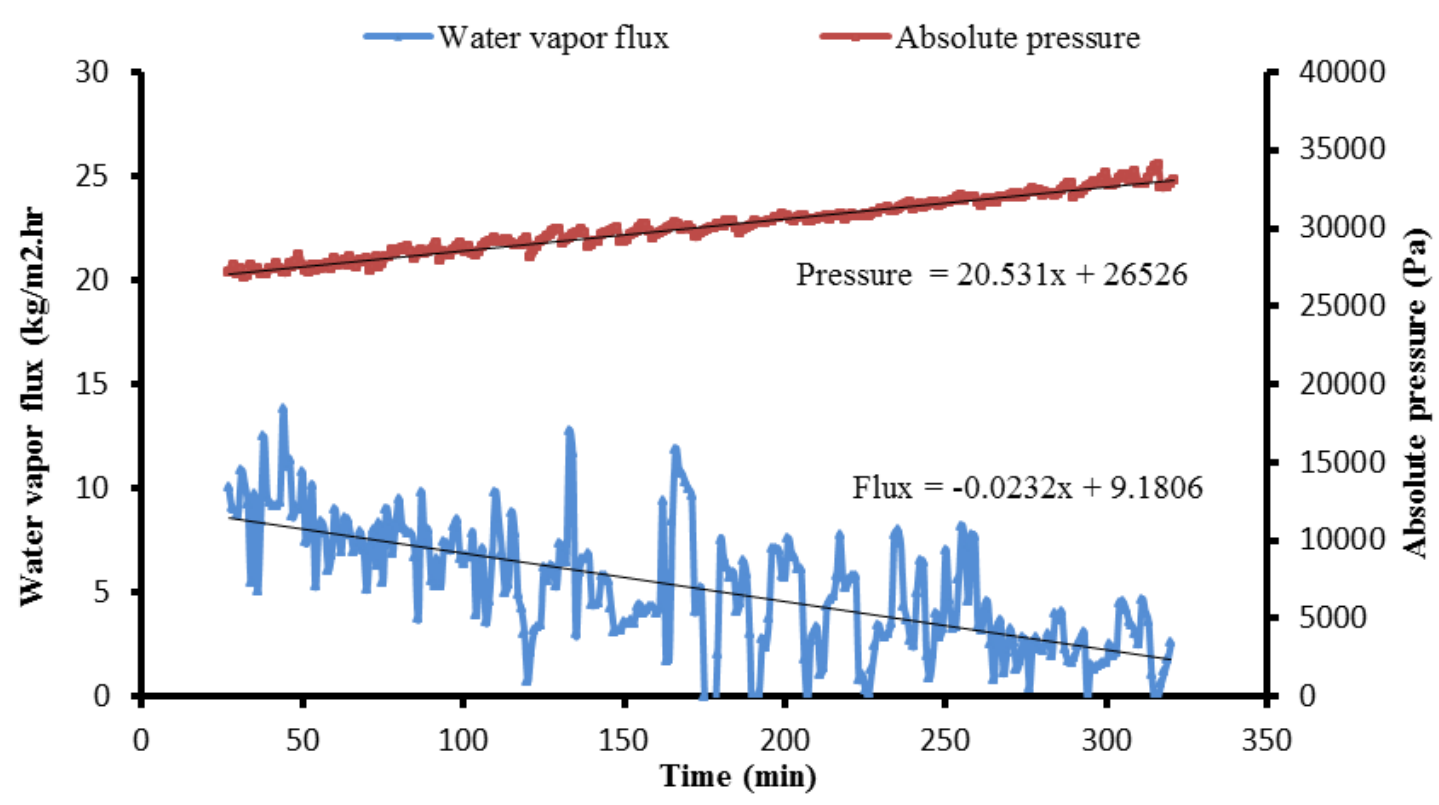

Figure 6: Water vapor flux and absolute pressure of M1VMD permeability test $v s$ time (feed flow rate $=2 \mathrm{~L} / \mathrm{min}$, bulk feed temperature $=70^{\circ} \mathrm{C}$ ).

Under the assumption that the temperature of the feed side remains constant over time then the variation in the water vapor flux should be caused by the variation of the absolute pressure of the VMD permeate side only. Mathematically, this can be written as:

$$
\frac{d P_{v}}{d t}=\frac{d \Delta P}{d t}
$$

where $P_{v}$ is the permeate absolute pressure and $t$ is the time. 


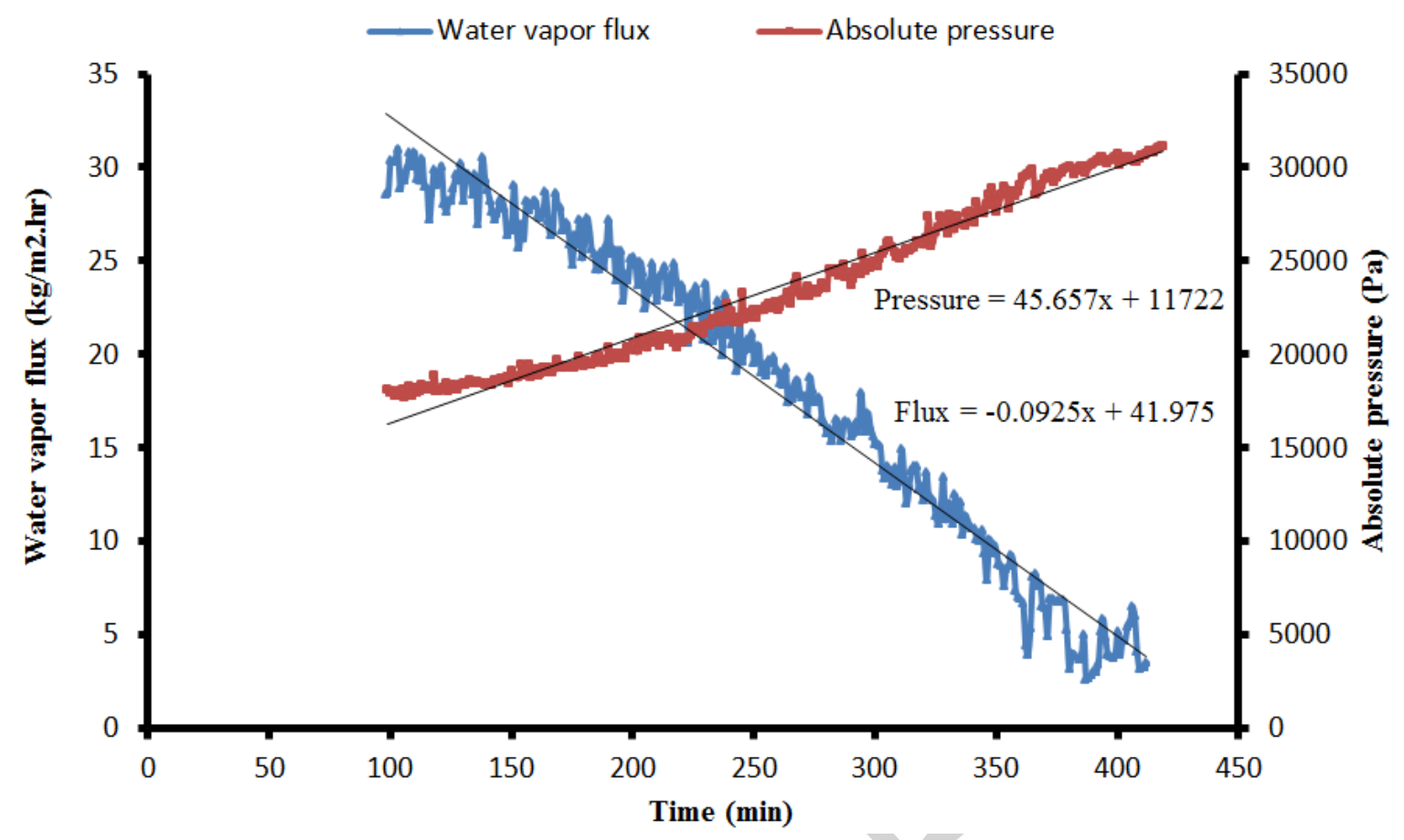

Figure 7: Water vapor flux and absolute pressure of M2 VMD permeability test $v$ s time (feed flow rate $=2 \mathrm{~L} / \mathrm{min}$, bulk feed temperature $=70^{\circ} \mathrm{C}$ ).

The linearity of the change of the flux and absolute pressure over time along with the general flux equation can be used in calculating the membrane permeability according to the following equations:

$$
\begin{gathered}
J=C \Delta \mathrm{P} \\
C=\frac{\frac{d J}{d t}}{\frac{d \Delta P}{d t}}=\frac{J}{\Delta P}
\end{gathered}
$$

where $\mathrm{C}$ is the mass transfer coefficient.

In simple words, the above equations mean that the membrane mass transfer coefficient can be calculated by dividing the slope of the water vapor flux versus time over the slope of the absolute pressure versus time. The calculated mass transfer coefficients of the tested membranes are shown in Table 2. The membrane mass transfer coefficients measured by VMD and gas permeance test were very close to each other and both showed that M2 has higher mass transfer coefficient than M1. In the sub-atmospheric modeling we used the averaged mass transfer coefficient of both methods. 
Table 2: Membranes mass transfer coefficients as measured by gas and VMD permeance methods.

\begin{tabular}{lll}
\hline \multirow{2}{*}{ Membrane } & \multicolumn{2}{l}{ Membrane mass transfer coefficient $(\mathrm{kg} / \mathrm{m} 2 . \mathrm{hr} . \mathrm{Pa})$} \\
\cline { 2 - 3 } & Gas permeance test & VMD permeance test \\
\hline M1 & 0.0010 & 0.0011 \\
M2 & 0.0019 & 0.0020 \\
\hline
\end{tabular}

\subsection{Mathematical model prediction}

\subsubsection{Effect of feed temperature}

The model validation started by comparing the flux predicted by the mathematical model to the experimentally measured flux at three different feed temperatures $\left(60^{\circ} \mathrm{C}, 70^{\circ} \mathrm{C}\right.$, and $\left.80^{\circ} \mathrm{C}\right)$. As shown in Figure 8, the model prediction almost matches the experimental data without significant errors except below the saturation pressure of the hot feed which reached about $20 \%$ at feed temperature of $80^{\circ} \mathrm{C}$. It is worth mentioning here that running the AGMD process under sub-atmospheric pressure enhanced the flux of the process by more than $300 \%$ when the subatmospheric pressure is at the saturation pressure of the bulk feed temperature. 


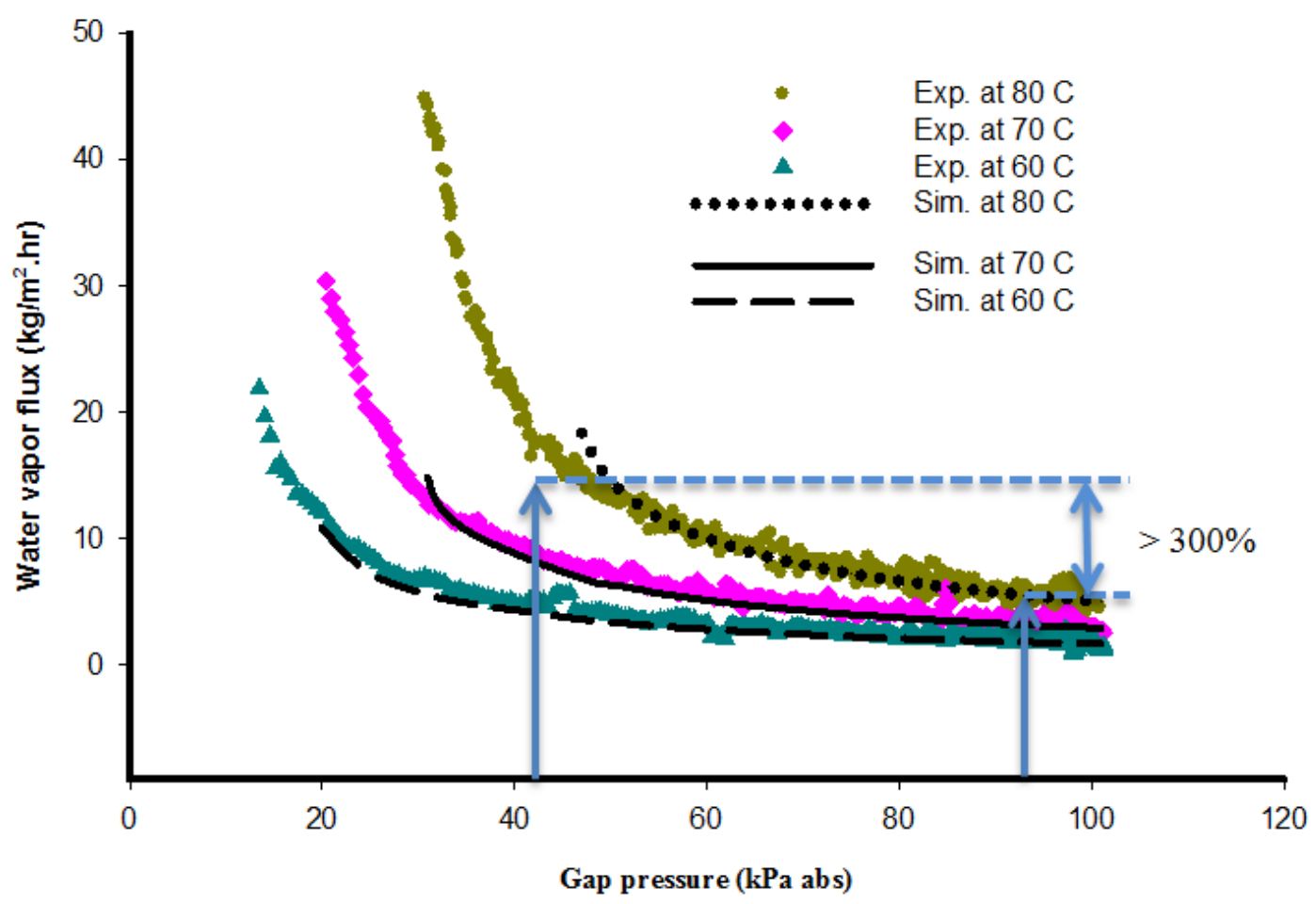

Figure 8: Simulated and experimental water vapor flux $v s$ gap pressure at different feed temperatures $\left(60^{\circ} \mathrm{C}, 70^{\circ} \mathrm{C}\right.$, and $80^{\circ} \mathrm{C}$ ) and at different gap pressures (below saturation pressure 1 atm).

\subsubsection{Effect of gap width}

The model prediction of the flux at different gap widths were also compared to the measured fluxes and the results are shown in Figure 9. The matching between the simulated fluxes and experimental data was reasonably good and the little deviation can be attributed to errors made in measuring the gap widths especially for the small gap. In the same figure, it is interestingly enough to see the experimental and simulated data converge at the saturation temperature where all non-condensable gases are removed. These data support our hypothesis that states AGMD gap width becomes unimportant if non-condensable gases are removed. 


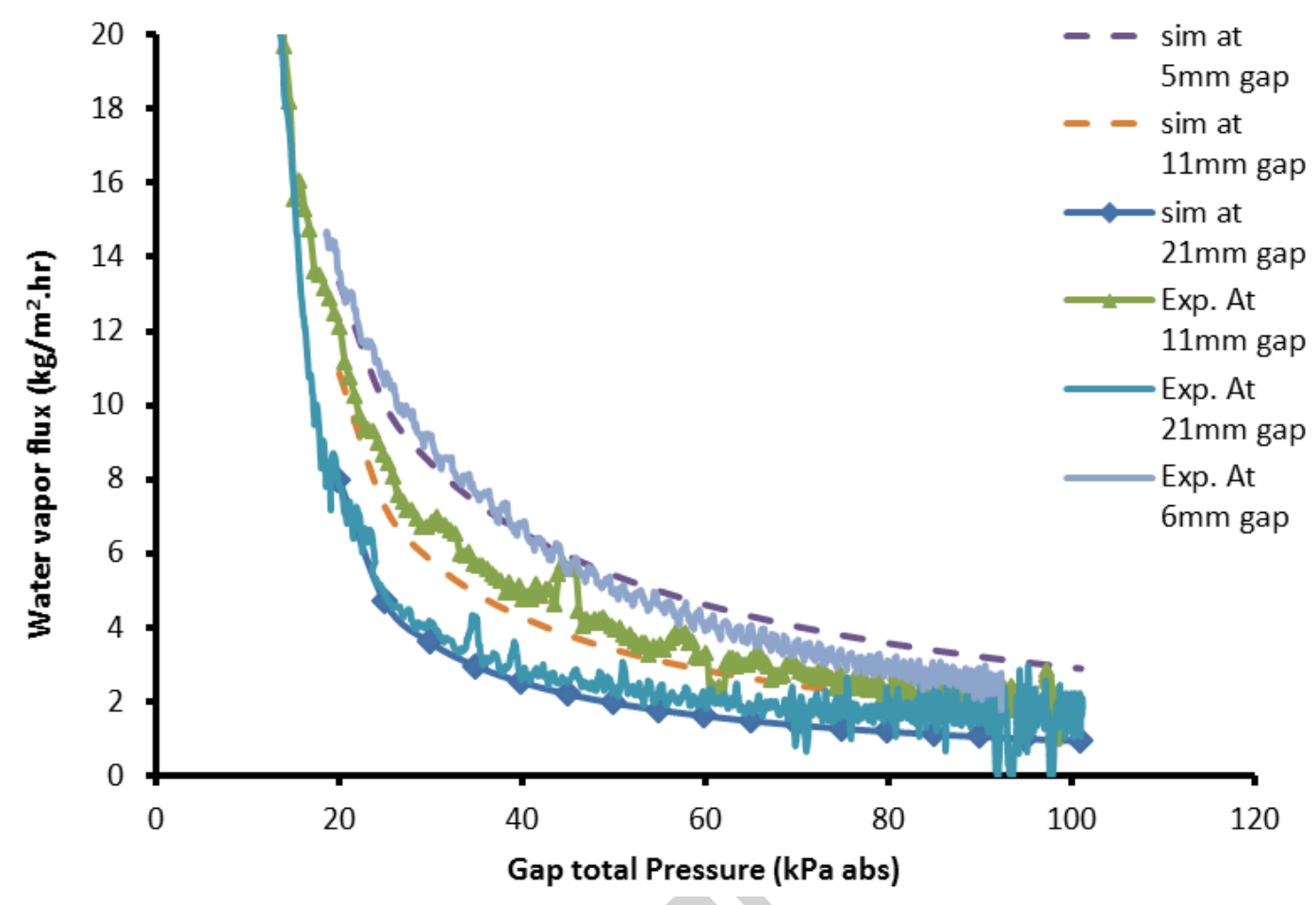

Figure 9: Experimental and simulated water vapor flux vs different gap pressure $\left(\mathrm{P}_{\text {sat: }}: 1 \mathrm{~atm}\right)$ at three different gap widths $(5 \mathrm{~mm}, 11 \mathrm{~mm}$, and $21 \mathrm{~mm}), \mathrm{T}_{\mathrm{f}}=60^{\circ} \mathrm{C}$

\subsubsection{Effect of mass transfer coefficient}

The effect of membrane mass transfer coefficient is shown in Figure 10.

The agreement between modeling and experimental data is very good as well. As expected, Figure 10 shows that the membrane mass transfer coefficient becomes important only when all non-condensable gases are completely removed from the AGMD gap. Even though Prince et al., [24] specified the optimum gap width to be $2-4 \mathrm{~mm}$; it is clear from Figure 9 that the gap width becomes unimportant if all non-condensable gases are removed completely from the air gap.

In Figure 10, although M2 has higher mass transfer coefficient, water vapor flux is almost the same as that of M1 when the system is operated at absolute pressure higher than the saturation pressure of the feed temperature, which means that the membrane's mass transfer resistance becomes less important if non-condensable gases are present in the module gap. 


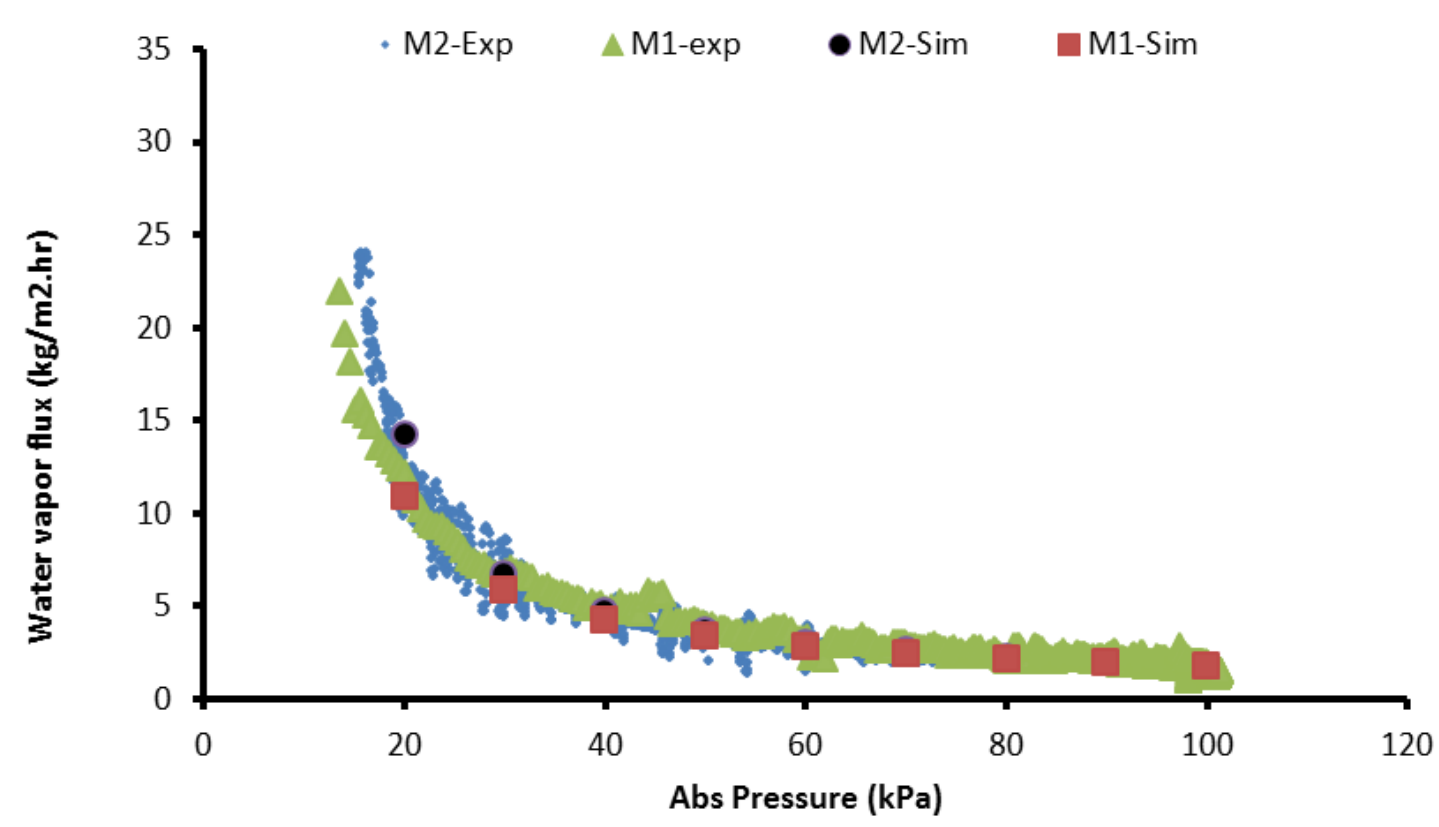

Figure 10: Water vapor flux $v s$ different gap pressure $\left(\mathrm{P}_{\text {sat }}: 1 \mathrm{~atm}\right)$ of two different membranes (M1 and M2) having different mass transfer coefficients, $\mathrm{T}_{\mathrm{f}}=60^{\circ} \mathrm{C}$.

\subsubsection{Effect of coolant temperature}

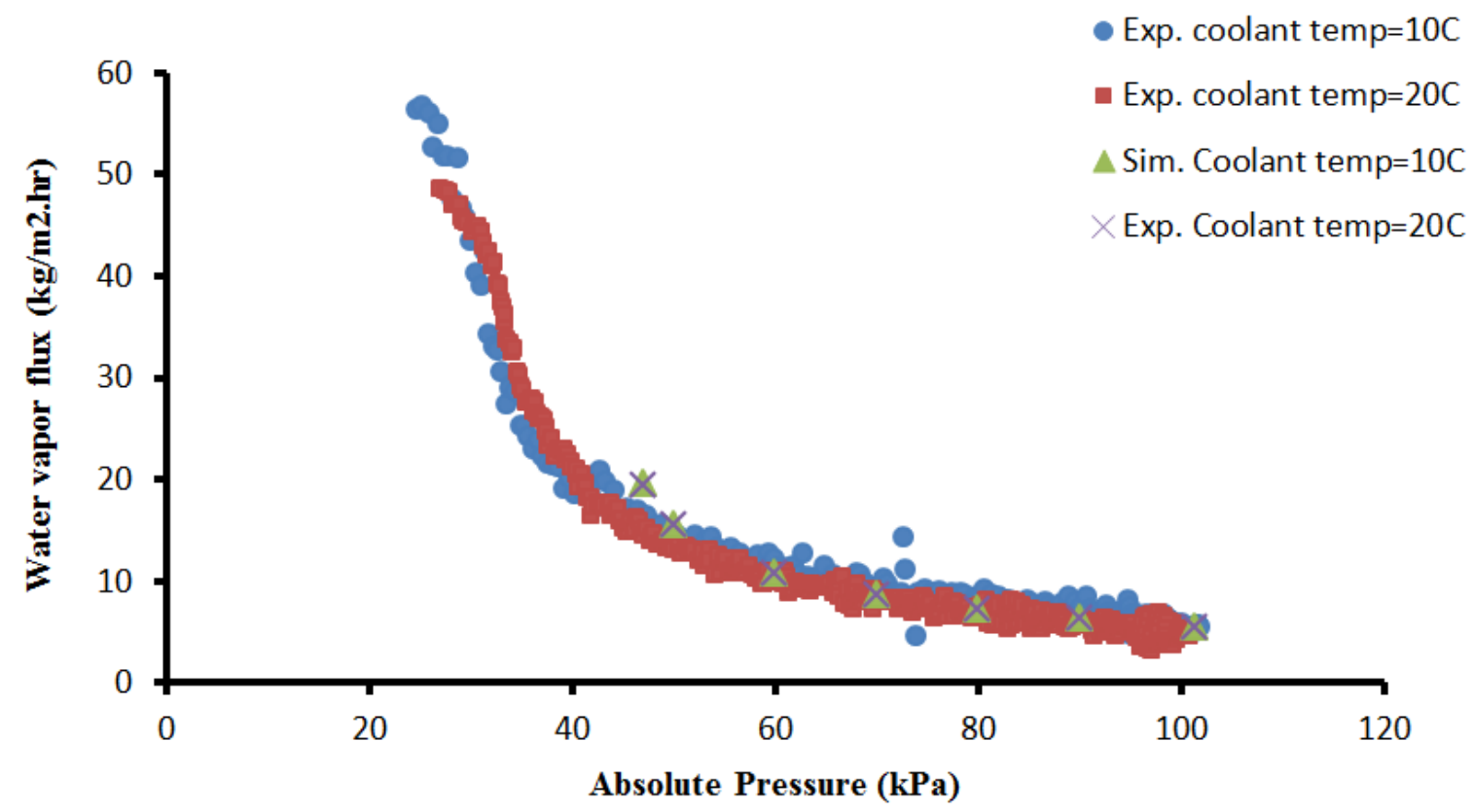

Figure 11: Simulated and experimental tests $v s$ absolute pressure for two different coolant temperatures $\left(\mathrm{T}_{\mathrm{f}}=80^{\circ} \mathrm{C}\right)$. 
As long as the coolant temperature is far below the gap saturation pressure, the coolant temperature will be sufficient to condense the entire vapor generated by the MD process. Therefore, further decreasing the coolant temperature is not expected to cause any appreciable improvement to the process performance. As it can be seen in Figure 11, the simulated and experimental data almost fall on the same curve for two different coolant temperatures and at constant feed temperature $\left(80^{\circ} \mathrm{C}\right)$, which confirms that the non-appreciable effect of coolant temperature on water vapor flux. However, the coolant temperature is expected to have significant effect on the flux with large modules (scale-up) when both feed and coolant temperatures approach each other (small T throughout the module length) [2-5, 7, 32].

\section{Staging sub-atmospheric AGMD modules}

Modeling and experimental data presented in Figures 8-11 showed that reducing the gap absolute pressure increases the process flux due to the removal of the mass transfer resistance caused by the non-condensable gases. However, the more we reduce the gap pressure below the saturation pressure of the feed temperature, the lower the cooling temperature is needed for condensing the water vapor. Therefore, from a practical point of few the gap pressure should be slightly below the saturation pressure of the feed temperature to assure the complete removal of noncondensable gases and to sustain enough driving force for the water vapor to overcome the membrane structure mass transfer resistance. This pressure also should be high enough to allow the water vapor to condense on the cooling plate surface maintained at temperatures slightly lower than the saturation temperature of the water vapor.

In previous work [11] it was shown that the feed temperature decreases as the membrane length increases due to the heat loss through evaporation. Such decrease in temperature creates a practical difficulty in maintaining the gap pressure at the saturation pressure of the feed temperature in a single module. An engineering solution to this problem is already practiced in conventional thermal desalination technology, such as MSF, through staging the evaporation and condensation processes. When the feed temperature decreases by $3^{\circ} \mathrm{C}$, for example, in the first stage due to evaporation, it flows into another distiller (next stage) where the pressure is lowered to match the saturation pressure at that feed temperature and so on (for the next stages). Figure 
12 shows that in order to maintain the pressure at the saturation pressure of the feed temperature, infinite stages are required. However, since this is not practically possible, conventional thermal desalination uses one stage for every $2-3^{\circ} \mathrm{C}$ reduction in feed temperature (in MSF brine recirculation design 24 stages are typically used). In this way, the highest absolute pressure is applied at the first stage while the lowest one is maintained at the last stage where feed temperature is the lowest.

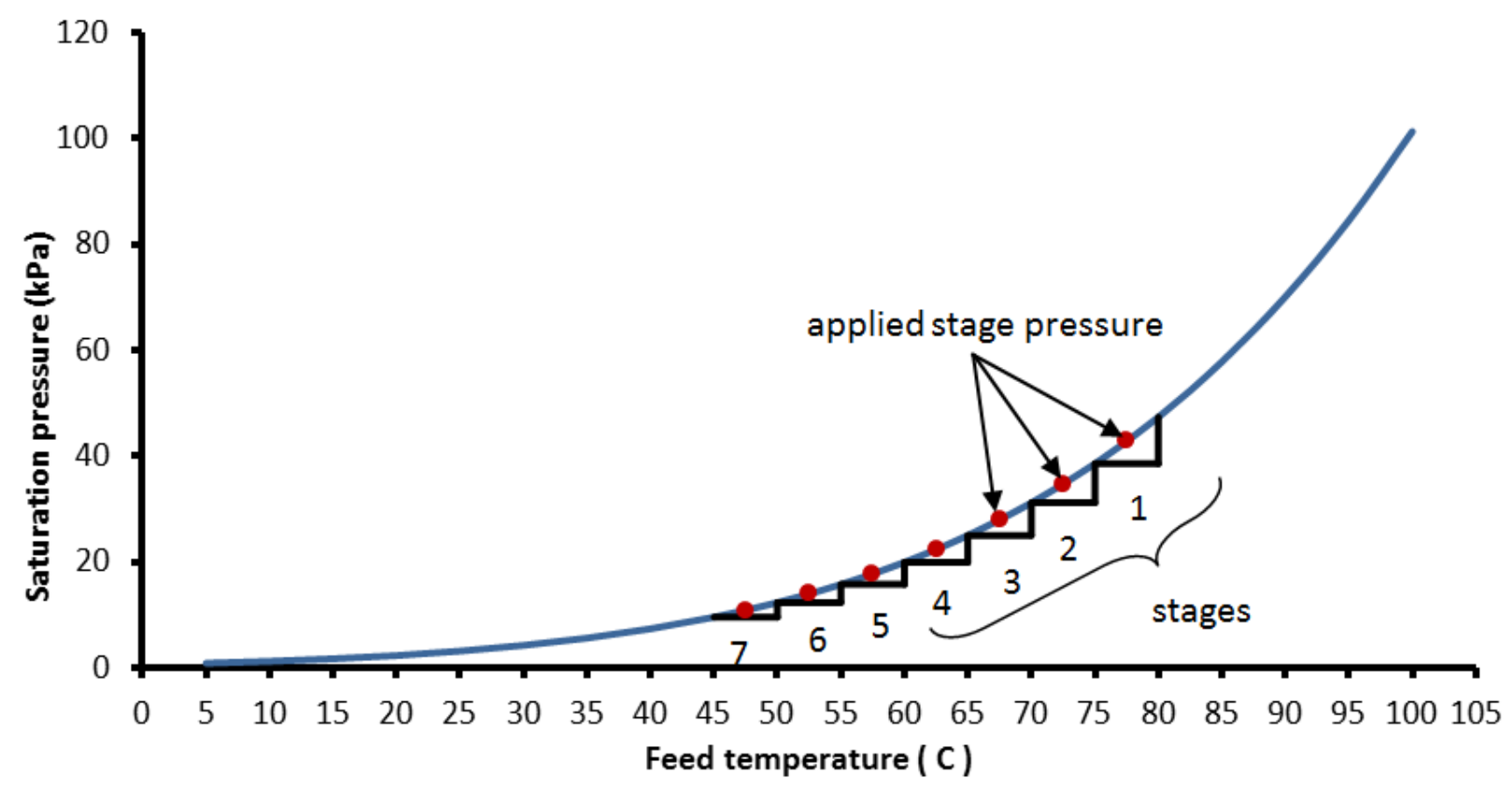

Figure 12: Maintaining the evaporating medium condition at the vapor pressure -temperature equilibrium curve through staging.

Similarly, sustaining high flux of the AGMD can be achieved by staging the process modules in series as it is the case in MSF.

To prove the hypothesis of such a practice, our mathematical model is used to simulate different sub-atmospheric AGMD processes made up of different modules (stages) along the feed flow. All processes have the same flow rate of $100 \mathrm{~kg} / \mathrm{h}$ that enter at $4.2 \mathrm{wt} \%$ salinity and $70^{\circ} \mathrm{C}$ (feed in) and exits at $40^{\circ} \mathrm{C}$ (feed out or brine). The coolant enters all processes at the same flow rate as the feed and its temperature is maintained at $5^{\circ} \mathrm{C}$ lower than the feed temperature along the membrane surface area. Every module gap pressure is maintained at the saturation 
pressure of the feed temperature that enters each module (see Figure 13 for illustration). Since the overall distillate production rate depends only on the temperature difference between the inlet and outlet temperatures of the feed [11], all processes should have the same distillate production rate but their average fluxes will be different. Therefore, different membrane surface area is required to achieve the same production rate for each process.
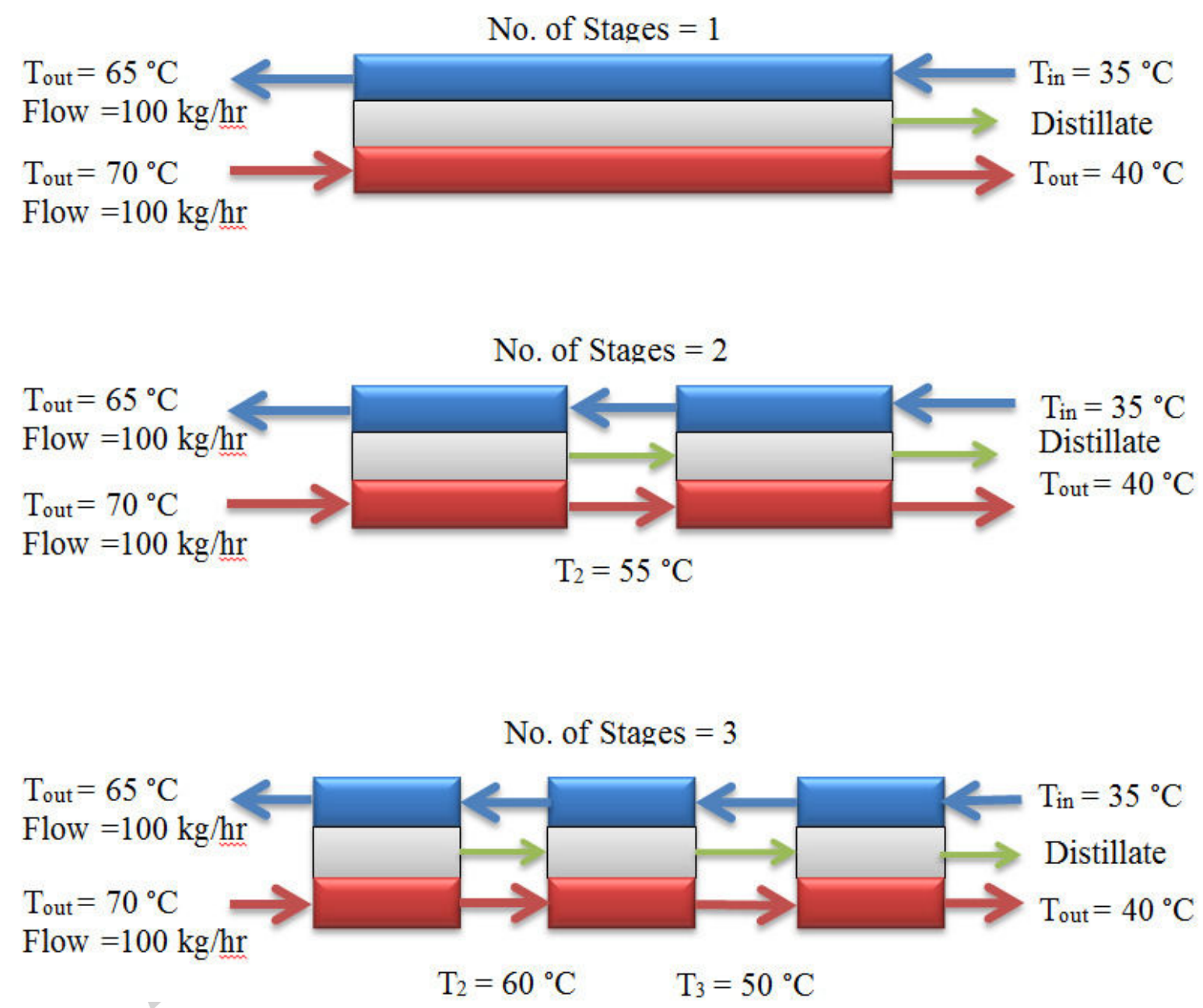

Figure 13: Illustration of sub-atmospheric AGMD staging. 


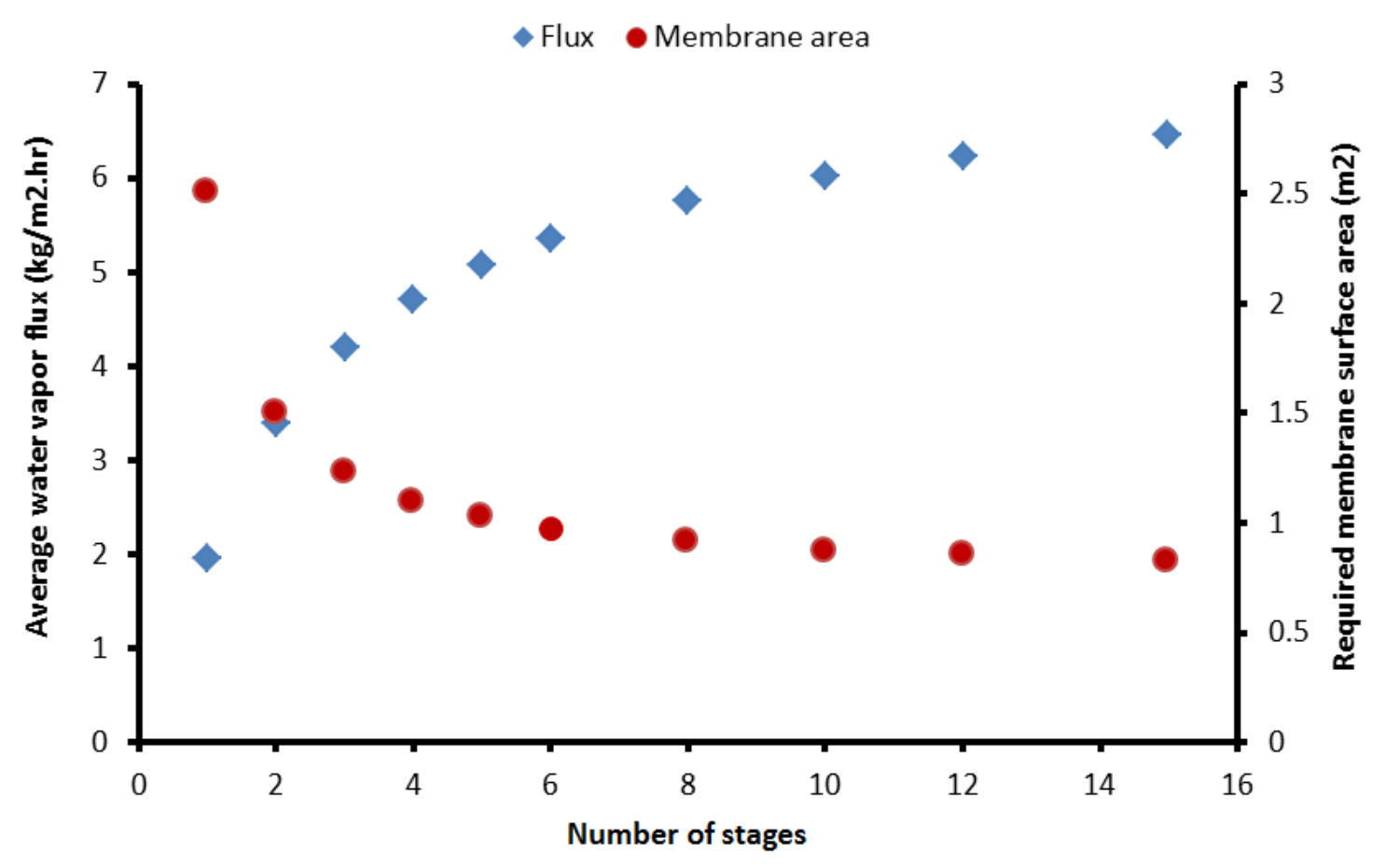

Figure 14: Simulating the staging effect of sub-atmospheric AGMD on the flux and the required membrane area (producing the same capacity).

As shown in Figure 14, the flux increases as the number of stages increases. The higher the number of stages, the better controllability we have on the absolute pressure inside the module gap which in its turn leads to higher water vapor flux. A three-fold flux increase can be achieved by using 10 modules $\left(3^{\circ} \mathrm{C} /\right.$ stage $)$ instead of one under the same in/out operating conditions. As expected, the same figure shows that the increase of the average flux reduces the required membrane area. This means that staging sub-atmospheric AGMD process is expected to reduce its capital cost if we ignore the cost of the vacuum system. However, one should note that reducing the feed temperature drop per stage to lower than $3{ }^{\circ} \mathrm{C} /$ stage does not significantly decrease the required membrane area. Therefore, the module fabrication cost as well as the cost of operating the vacuum system may exceed the savings made through reducing the required membrane surface area. An optimization study might be required to seek a balance between these costs. 


\section{Conclusions}

The simulated and experimental results proved that removing non-condensable gases from the AGMD gap increases the flux by more than three times when the gap pressure is maintained at the saturation pressure of the feed temperature. It was also shown that the gap width becomes less important at the absence of non-condensable gases. Additionally, the mathematical model was able to prove that staging the AGMD process operating under sub-atmospheric pressure is very essential for scaling up the process and it gives better control over the gap pressure as the feed temperature decreases due to evaporation. Thus, we believe the staging practice will help in sustaining the water vapor flux along the AGMD process and in lowering its capital cost by using less membrane surface area. On the other hand, the use of vacuum system for the removal of non-condensable gases will increase the operating cost of the process.

\section{Nomenclature}

A Sample holder surface area $\left(\mathrm{m}^{2}\right)$

b Membrane thickness (m)

C Membrane mass transfer coefficient $\left(\mathrm{kg} / \mathrm{m}^{2} \cdot \mathrm{hr} \cdot \mathrm{Pa}\right)$

d Membrane pore size (m)

$\mathrm{D}_{\mathrm{AB}} \quad$ Diffusion coefficient of water vapor in air $\left(\mathrm{m}^{2} / \mathrm{s}\right)$

$\Delta \mathrm{P} \quad$ Pressure difference $(\mathrm{kPa})$

$\mathrm{J}_{\mathrm{AGMD}}$ Total mass flux of the AGMD $\left(\mathrm{kg} / \mathrm{m}^{2} . \mathrm{hr}\right)$

$\mathrm{J}_{\mathrm{m}} \quad$ Mass flux cross the membrane $\left(\mathrm{kg} / \mathrm{m}^{2} . \mathrm{hr}\right)$

$\mathrm{J}_{\text {gap }}$ Mass flux across the airgap $\left(\mathrm{kg} / \mathrm{m}^{2} . \mathrm{hr}\right)$

$\mathrm{J}_{\mathrm{mv}} \quad$ Water vapor flux by molecular diffusion $\left(\mathrm{kg} / \mathrm{m}^{2} \cdot \mathrm{hr}\right)$

$\mathrm{J}_{\mathrm{kv}} \quad$ Knudsen mass flux of water vapor $\left(\mathrm{kg} / \mathrm{m}^{2} \cdot \mathrm{hr}\right)$

$\mathrm{J}_{\mathrm{p}} \quad$ Vapor flux of the viscous flow regime $\left(\mathrm{kg} / \mathrm{m}^{2} . \mathrm{hr}\right)$

$\mathrm{M}_{\mathrm{v}} \quad$ Molecular weight of water vapor $(\mathrm{kg} / \mathrm{kmole})$

$\mathrm{M}_{\mathrm{g}} \quad$ Molecular weight of a gas $(\mathrm{kg} / \mathrm{kmole})$

$\mathrm{P}_{\mathrm{o}} \quad$ Standard gas pressure $(101.325 \mathrm{kPa})$

$\mathrm{P}_{\mathrm{ma}} \quad$ Water vapor partial pressure at the air gap and membrane interface $(\mathrm{Pa})$

$\mathrm{P}_{\mathrm{hm}} \quad$ Water vapor partial pressure at the membrane and hot feed interface $(\mathrm{Pa})$ 


$\begin{array}{ll}\mathrm{P}_{\mathrm{avg}} & \text { Average gas pressure (Pa) } \\ \mathrm{R} & \text { Universal gas constant } \\ \mathrm{R}_{\mathrm{v}} & \text { Total water vapor mass transfer resistance } \\ \mathrm{R}_{\mathrm{kv}} & \text { Mass transfer resistance due to Knudsen diffusion } \\ \mathrm{R}_{\mathrm{mv}} & \text { Mass transfer resistance due to molecular diffusion } \\ \mathrm{T}_{\mathrm{avg}} & \text { Average temperature inside the membrane }\left({ }^{\circ} \mathrm{C}\right) \\ \mathrm{T} & \text { Time (hr) } \\ V & \text { Volumetric flow rate }\left(\mathrm{m}^{3} / \mathrm{hr}\right) \\ \mathrm{y} & \text { Mole fraction of water vapor } \\ & \\ \text { Greek symbols } \\ \varepsilon & \text { Membrane porosity } \\ \eta & \text { Gas viscosity (kg/m.s) } \\ \rho & \left.\text { Gas density (kg/m } \mathrm{m}^{3}\right) \\ \tau & \text { Membrane pores tortuosity }\end{array}$

\section{References}

[1] L.D. Tijing, Y.C. Woo, J.-S. Choi, S. Lee, S.-H. Kim, H.K. Shon, Fouling and its control in membrane distillation-A review, J Membrane Sci 475 (2015) 215-244.

[2] E. Guillén-Burrieza, G. Zaragoza, S. Miralles-Cuevas, J. Blanco, Experimental evaluation of two pilot-scale membrane distillation modules used for solar desalination, J Membrane Sci 409-410 (2012) 264-275.

[3] Z. Kui, W. Heinzl, F. Bollen, G. Lange, Godart Van Gendt, C.F. Hoong, Demonstrating solar-driven membrane distillation using novel memsys vacuum multi-effect-membranedistillation (V-MEMD) process, Singapore International Water Week, Suntec CitySingapore, 2011, 23-25.

[4] D. Winter, J. Koschikowski, M. Wieghaus, Desalination using membrane distillation: Experimental studies on full scale spiral wound modules, J Membrane Sci 375 (2011) 104112.

[5] A. Kullab, Desalination using Membrane Distillation: Experimental and Numerical Study, in KTH, 2011, Sweden. 
[6] M. Khayet, Membranes and theoretical modeling of membrane distillation: A review, Adv Coll Inter Sci 164 (2011) 56-88.

[7] J.H. Hanemaaijer, J. van Medevoort, A.E. Jansen, C. Dotremont, E. van Sonsbeek, T. Yuan, L. De Ryck, Memstill membrane distillation - a future desalination technology, Desalination 199 (2006) 175-176.

[8] L. Francis, N. Ghaffour, A. Al-Saadi, S.P. Nunes, G. L. Amy, Performance evaluation of the DCMD desalination process under bench scale and large scale module operating conditions, J Membrane Sci 455 (2014) 103-112.

[9] L.D. Tijing, J.-S. Choi, S. Lee, S.-H. Kim, H.K. Shon, Recent progress of membrane distillation using electrospun nanofibrous membrane. J Membrane Sci 453 (2014) 435-462.

[10] J.-P. Mericq, S. Laborie, C. Cabassud, Vacuum membrane distillation of seawater reverse osmosis brines, Wat Res 44 (2010) 5260-5273.

[11] A.S. Alsaadi, N. Ghaffour, J.D. Li, S. Gray, L. Francis, H. Maab, G.L. Amy, Modeling of air-gap membrane distillation process: A theoretical and experimental study, J Membrane Sci 445 (2013) 53-65.

[12] O.A. Hamed, M.A. Al-Sofi, G.M. Mustafa, M. Imam, K. Ba-Mardouf, H. Al-Washmi, Modeling and simulation of multistage flash distillation process. 4th SWCC Acquired Experience Conference, Riyadh, 2004.

[13] O.A. Hamed, K. Ba-Mardouf, H. Al-Washmi, K. Al-Shail, H. Abdullah, A. Al-Wadie, Assessment of the major design features of SWCC MSF desalination plants. 4th SWCC Acquired Experience Conference, Riyadh, 2004.

[14] A. Alkhudhiri, N. Darwish, N. Hilal, Membrane distillation: A comprehensive review, Desalination 287 (2012) 2-18.

[15] M. Khayet, T. Matsuura, Membrane distillation: principles and applications, Access Online via Elsevier, 2011.

[16] E. Curcio, E. Drioli, Membrane distillation and related operations - A review, Sep Purif Rev 34 (2005) 35-86.

[17] K.W. Lawson, D.R. Lloyd, Membrane distillation, J Membrane Sci 124 (1997) 1-25.

[18] A.S. Jonsson, R. Wimmerstedt, A.C. Harrysson, Membrane Distillation - a TheoreticalStudy of Evaporation through Microporous Membranes, Desalination 56 (1985) 237-249. 
[19] S. Kimura, S.I. Nakao, S.I. Shimatani, Transport Phenomena in Membrane Distillation, J Membrane Sci 33 (1987) 285-298.

[20] C. Gostoli, G. Sarti, S. Matulli, Low temperature distillation through hydrophobic membranes, Sep Sci Tech 22 (1987) 855-872.

[21] C.M. Guijt, G.W. Meindersma, T. Reith, A.B. de Haan, Air gap membrane distillation - 2. Model validation and hollow fibre module performance analysis, Sep Purif Tech 43 (2005) 245-255.

[22] K. Asano, Mass Transfer: From fundamentals to modern industrial applications, Wiley, 2007.

[23] J.G. Collier, J.R. Thome, Convective boiling and condensation, Oxford University Press, 1994.

[24] J.A. Prince, G. Singh, and, T.S. Shanmugasundaram, A vacuum air gap membrane distillation system for desalination, WO2013151498A1, google patent, 2013, http://www.google.com/patents/WO2013151498A1?cl=en.

[25] L. Francis, N. Ghaffour, A.A. Alsaadi, G.L. Amy, Material gap membrane distillation: A new design for water vapor flux enhancement, J Membrane Sci 448 (2013) 240-247.

[26] A. Alkhudhiri, N. Darwish, N. Hilal, Treatment of high salinity solutions: Application of air gap membrane distillation, Desalination 287 (2012) 55-60.

[27] R.W. Schofield, A.G. Fane, C.J.D. Fell, Gas and Vapor Transport through Microporous Membranes .1. Knudsen-Poiseuille Transition, J Membrane Sci 53 (1990) 159-171.

[28] Dao, T.D., et al., 2013. A new method for permeability measurement of hydrophobic membranes in Vacuum Membrane Distillation process. Wat Res 47, 2096-2104.

[29] W. Bing, K. Li, W.K. Teo, Preparation and characterization of poly (vinylidene fluoride) hollow fiber membranes for vacuum membrane distillation, J Appl Polymer Sci 106 (2007) 1482-1495.

[30] A. Alsaadi, L. Francis, H. Maab, G. Amy, N. Ghaffour, Experimental and theoretical analyses of temperature polarization effect in vacuum membrane distillation, $\mathrm{J}$ Membrane Sci 471 (2014) 138-148.

[31] L. Francis, H. Maab, A. AlSaadi, S. Nunes, N. Ghaffour, G.L. Amy, Fabrication of electrospun nanofibrous membranes for membrane distillation application, Desalin Water Treat 51 (2013) 1337-1343. 
[32] Y.D. Kim, K. Thu, N. Ghaffour, K.C. Ng, Performance investigation of solar-assisted hollow fiber DCMD desalination system, J Membrane Sci 427 (2013) 345-364. 


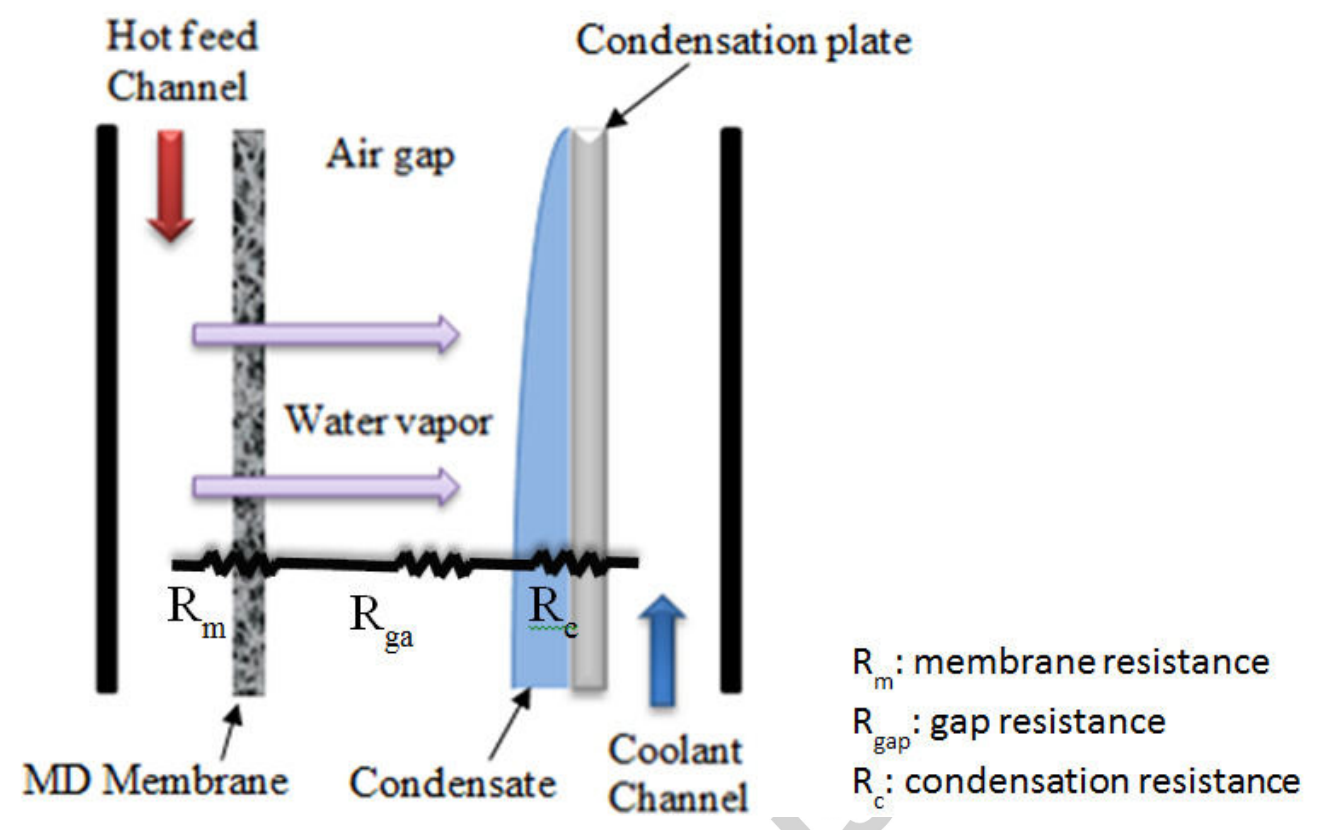

Figure 1: Mass transfer resistance across the air gap in a vertical flat sheet module. 

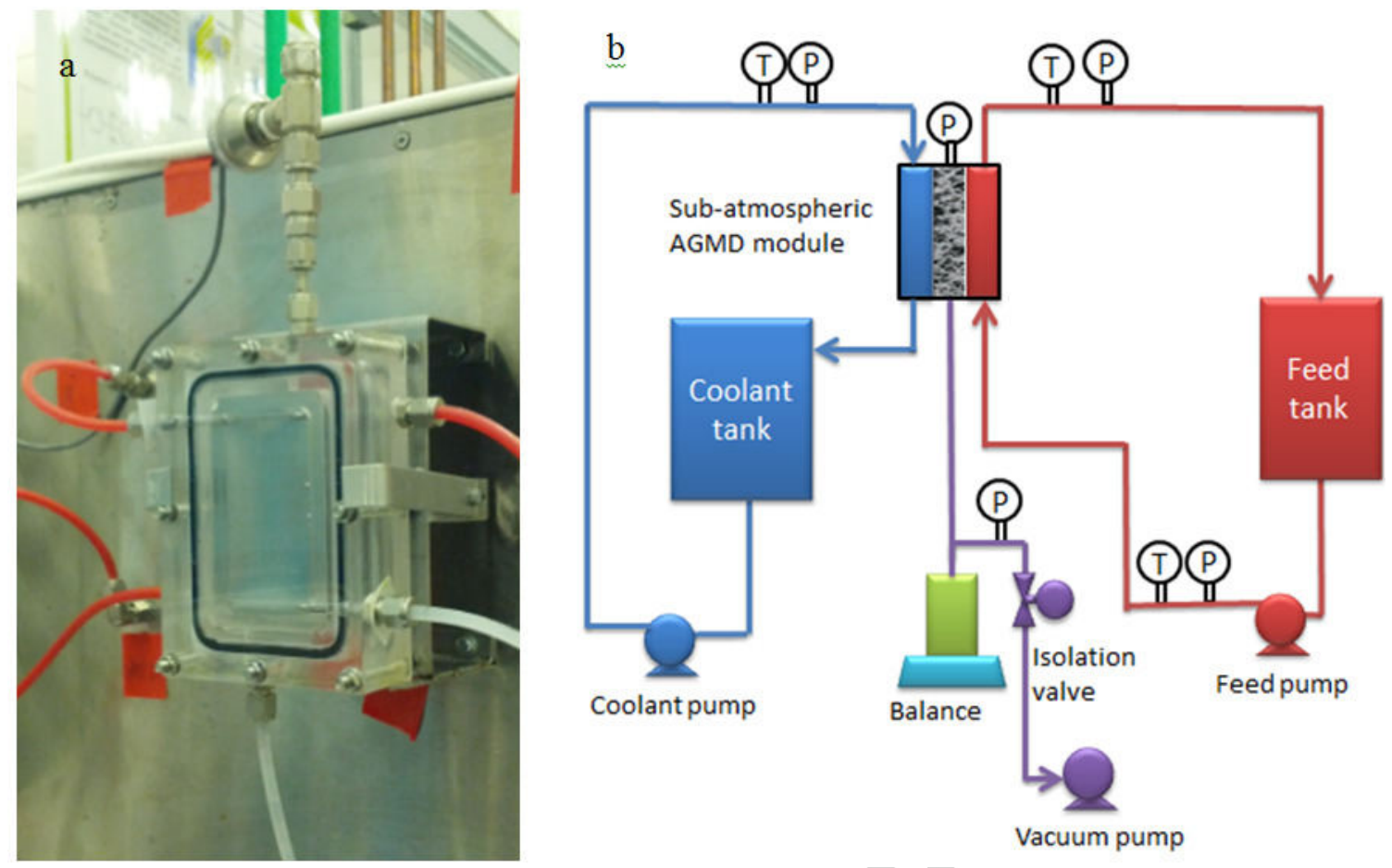

Figure 2: (a) Flat sheet sub-atmospheric AGMD module, (b) A schematic diagram of the subatmospheric AGMD experimental setup. 


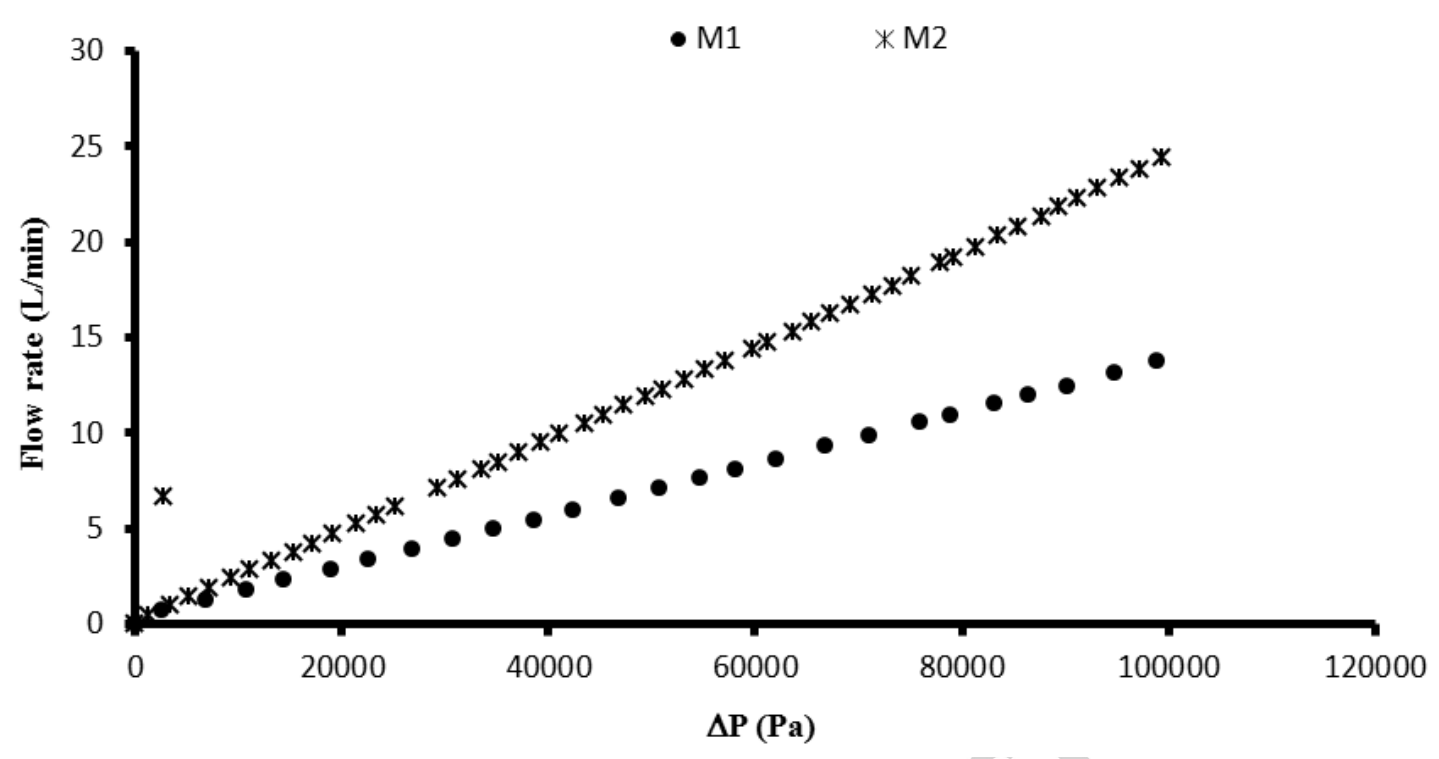

Figure 3: Gas permeance tests $v s \Delta \mathrm{P}$ for the two PTFE membranes. 


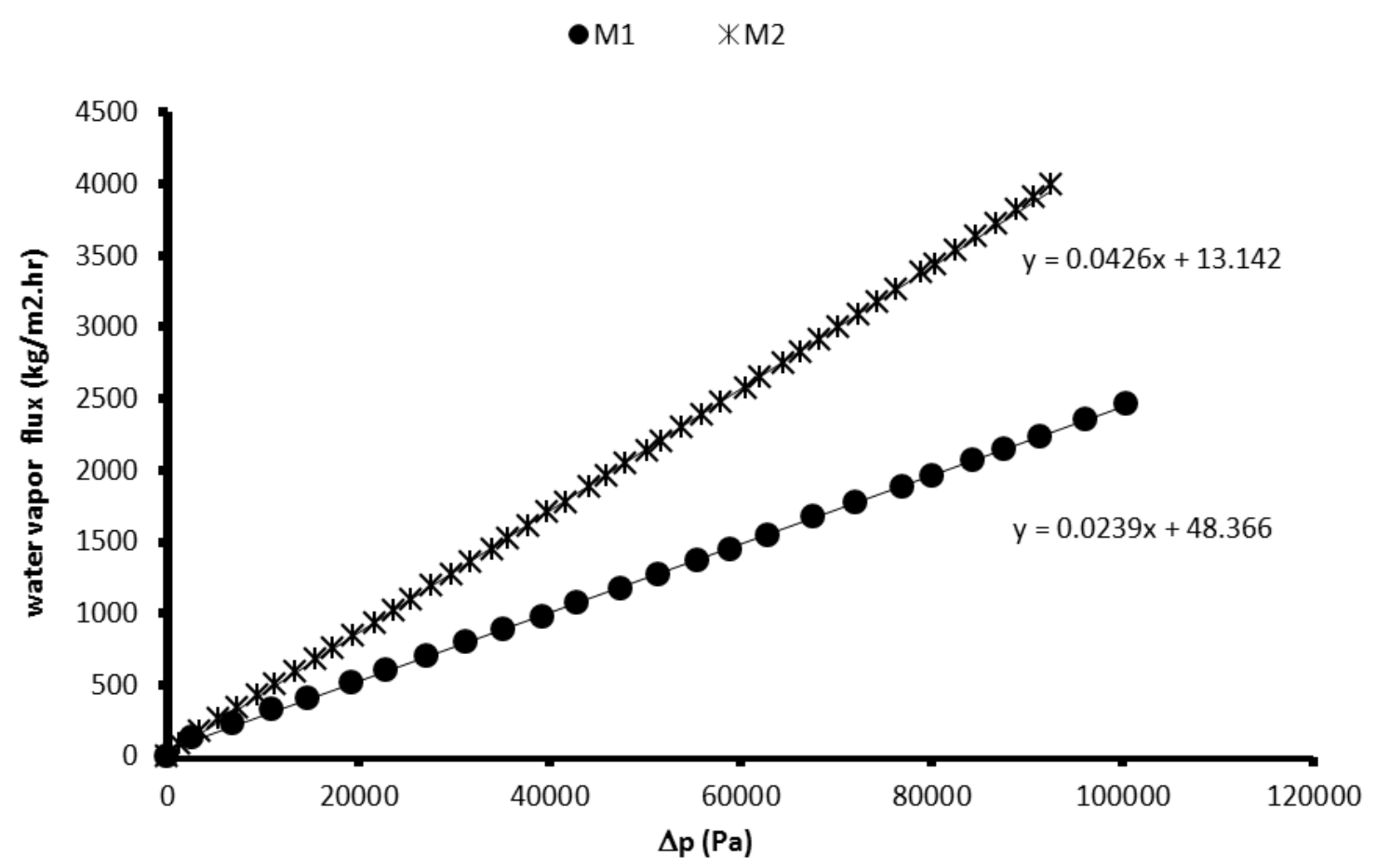

Figure 4: Water vapor flux vs $\Delta \mathrm{P}$ calculated under the gas permeance conditions. 


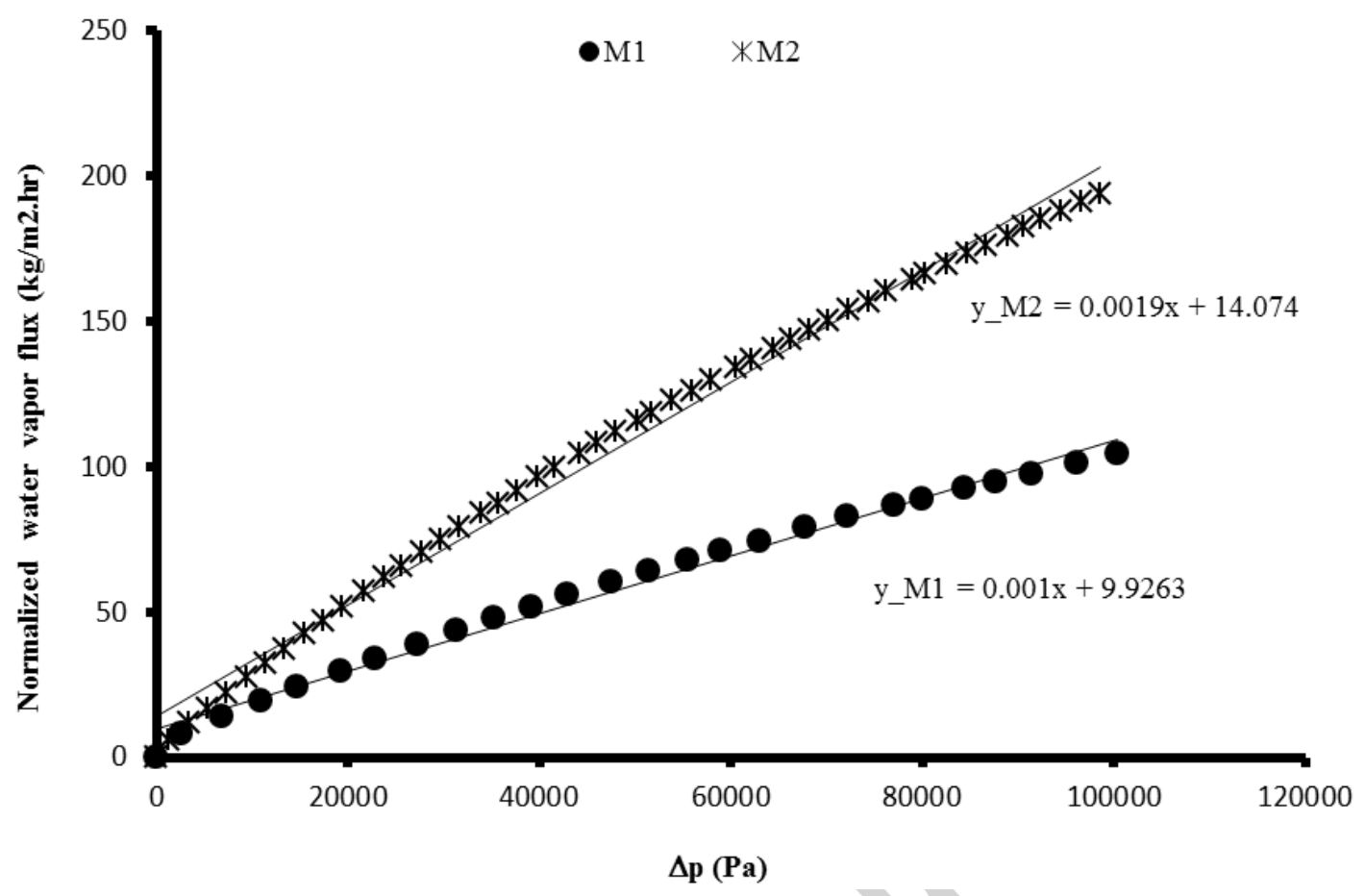

Figure 5: Normalized water vapor flux for density and viscosity $v s \Delta \mathrm{P}$ (data obtained from the gas permeance test). 


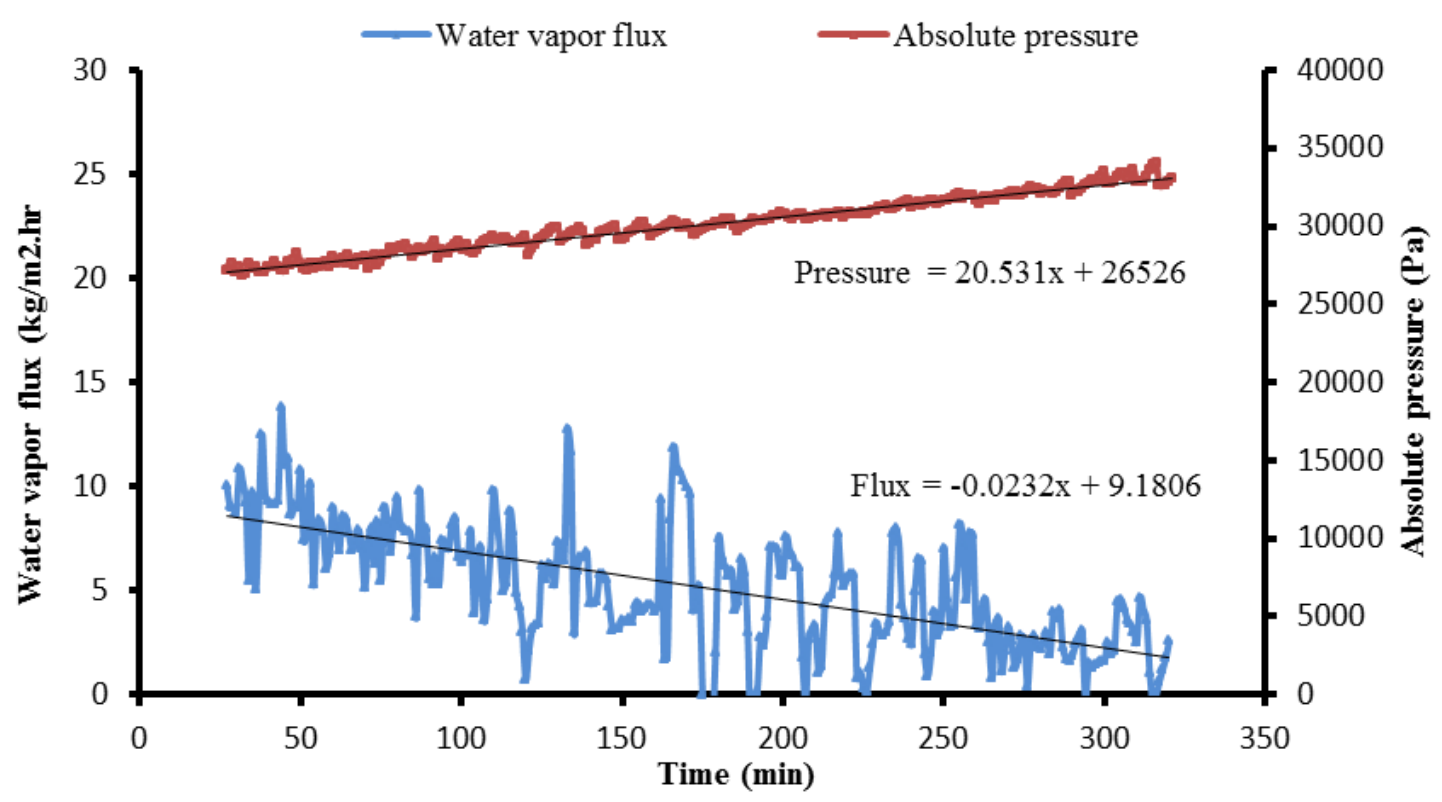

Figure 6: Water vapor flux and absolute pressure of M1VMD permeability test $v s$ time (feed flow rate $=2 \mathrm{~L} / \mathrm{min}$, bulk feed temperature $=70{ }^{\circ} \mathrm{C}$ ). 


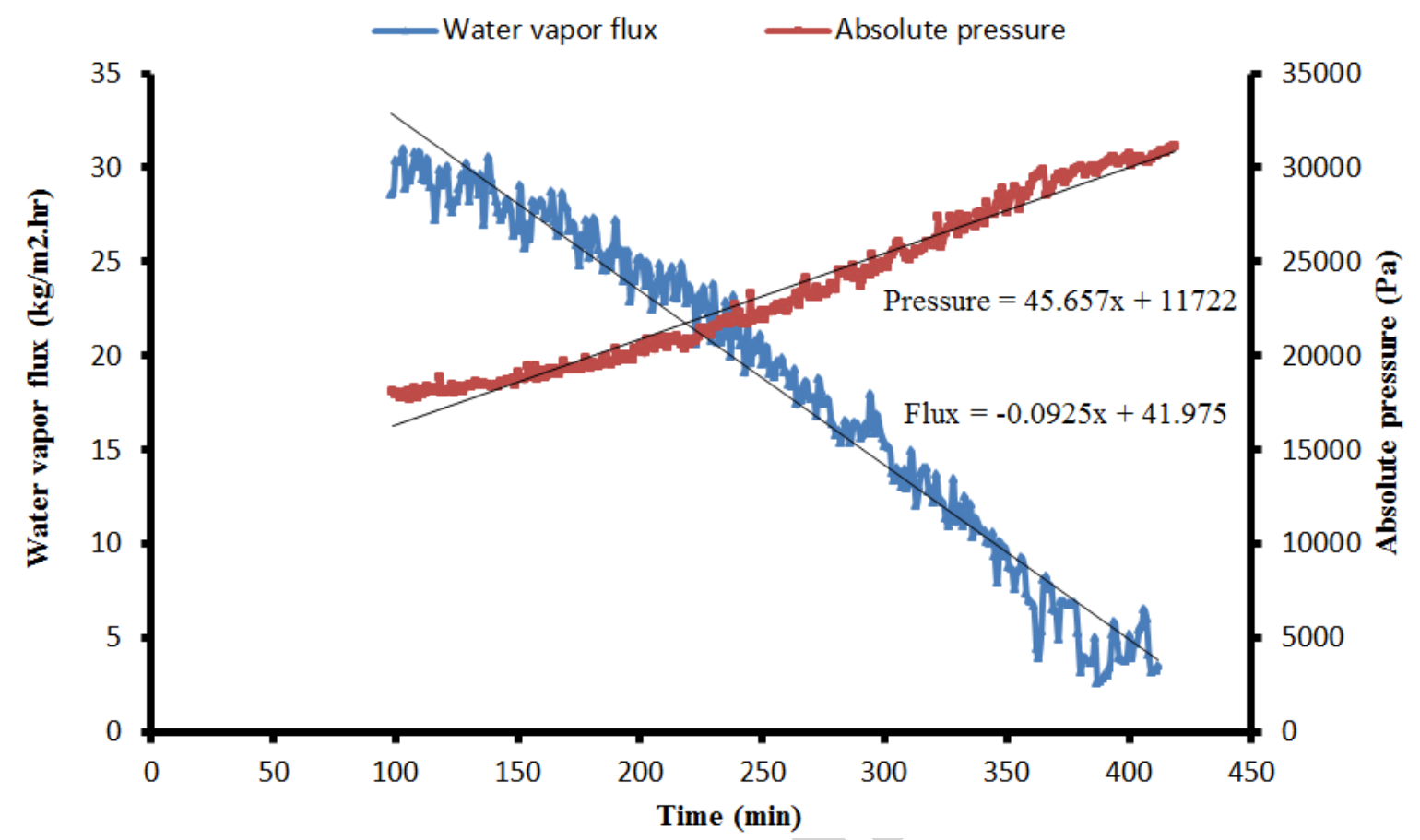

Figure 7: Water vapor flux and absolute pressure of M2 VMD permeability test $v s$ time (feed flow rate $=2 \mathrm{~L} / \mathrm{min}$, bulk feed temperature $=70{ }^{\circ} \mathrm{C}$ ). 


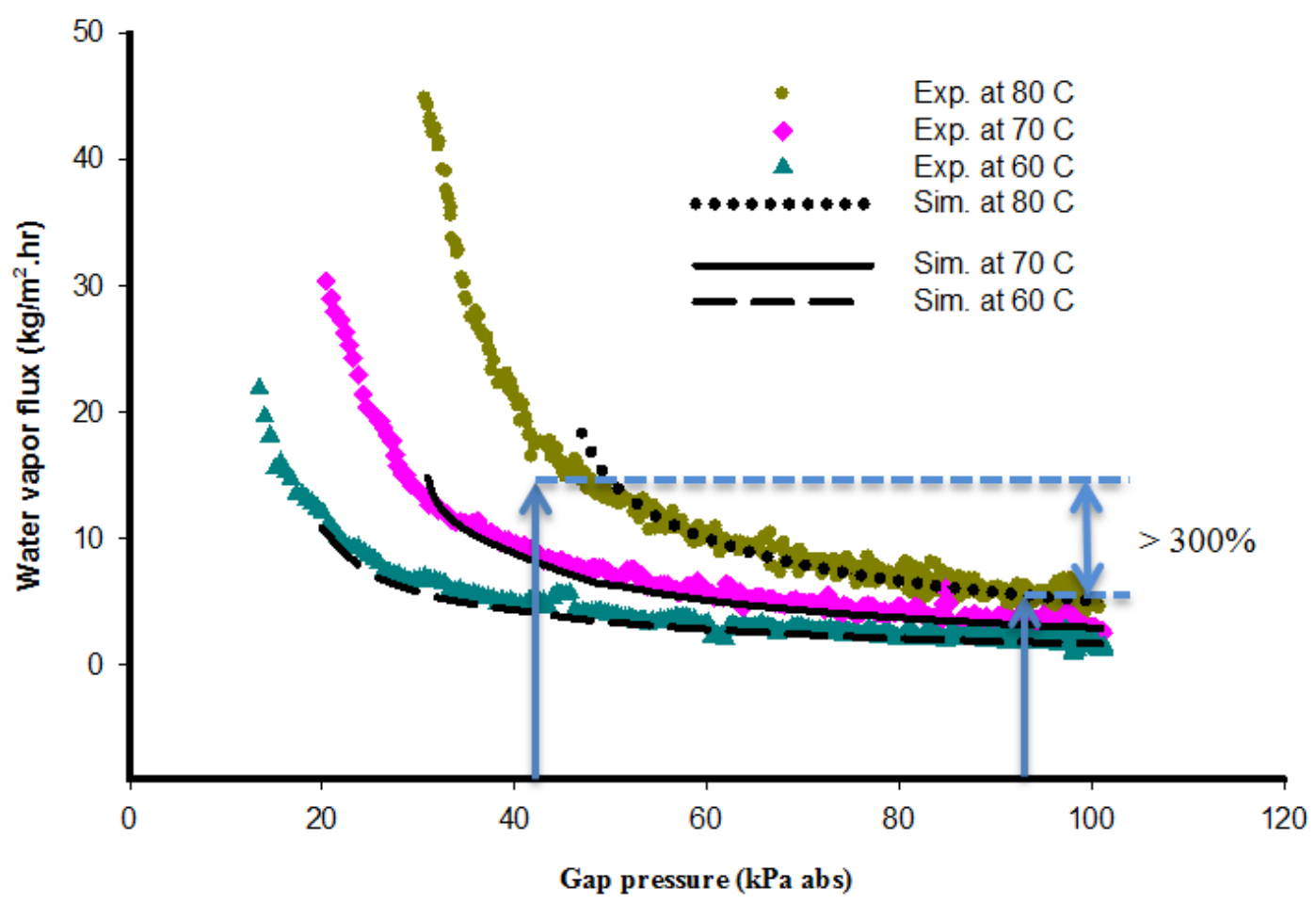

Figure 8: Simulated and experimental water vapor flux vs gap pressure at different feed temperatures $\left(60^{\circ} \mathrm{C}, 70^{\circ} \mathrm{C}\right.$, and $80^{\circ} \mathrm{C}$ ) and at different gap pressures (below saturation pressure 1 atm). 


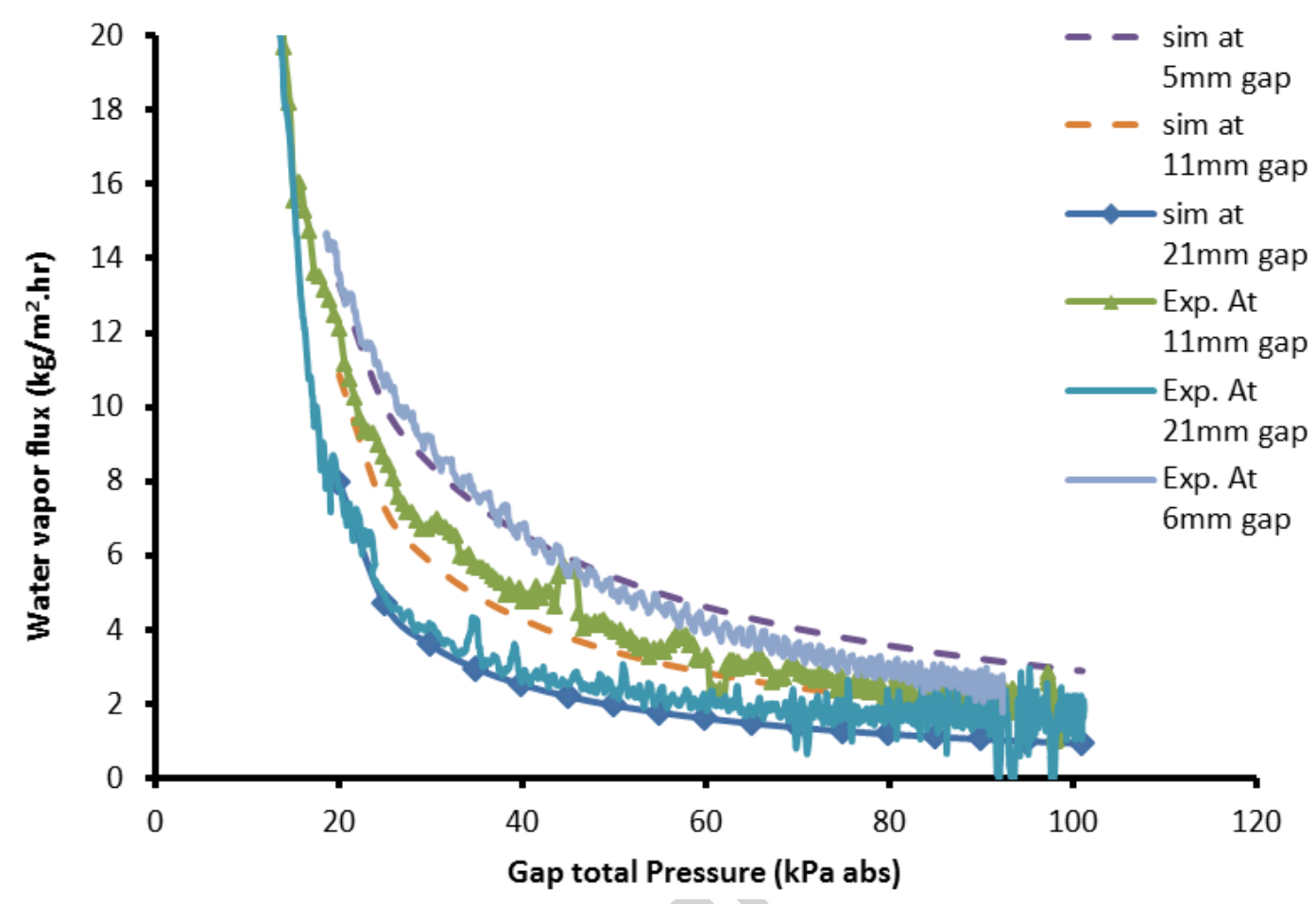

Figure 9: Experimental and simulated water vapor flux vs different gap pressure $\left(\mathrm{P}_{\text {sat }}: 1 \mathrm{~atm}\right)$ at three different gap widths $(5 \mathrm{~mm}, 11 \mathrm{~mm}$, and $21 \mathrm{~mm}), \mathrm{T}_{\mathrm{f}}=60^{\circ} \mathrm{C}$ 


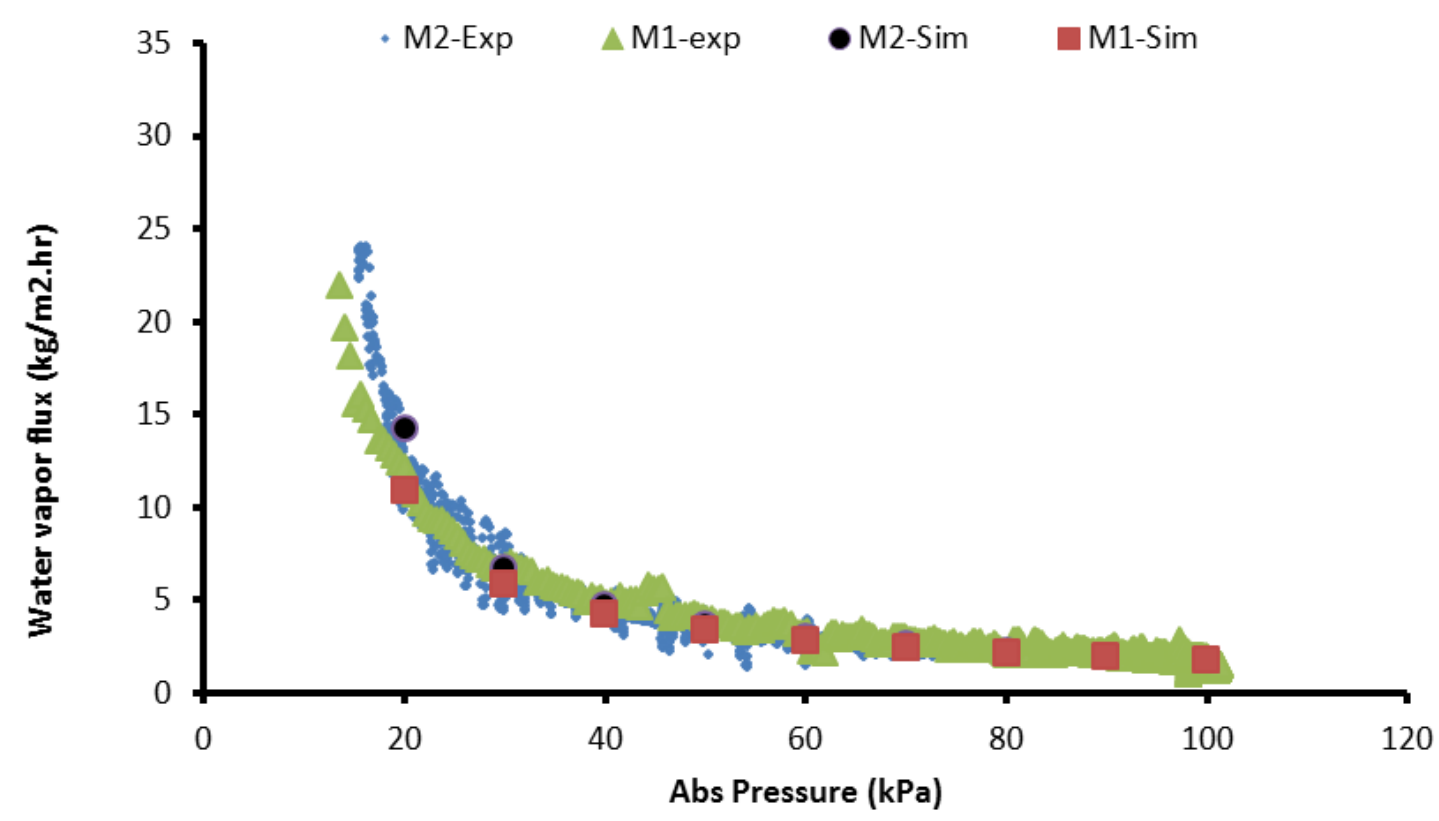

Figure 10: Water vapor flux $v s$ different gap pressure $\left(\mathrm{P}_{\text {sat }}: 1 \mathrm{~atm}\right)$ of two different membranes (M1 and M2) having different mass transfer coefficients, $\mathrm{T}_{\mathrm{f}}=60^{\circ} \mathrm{C}$. 


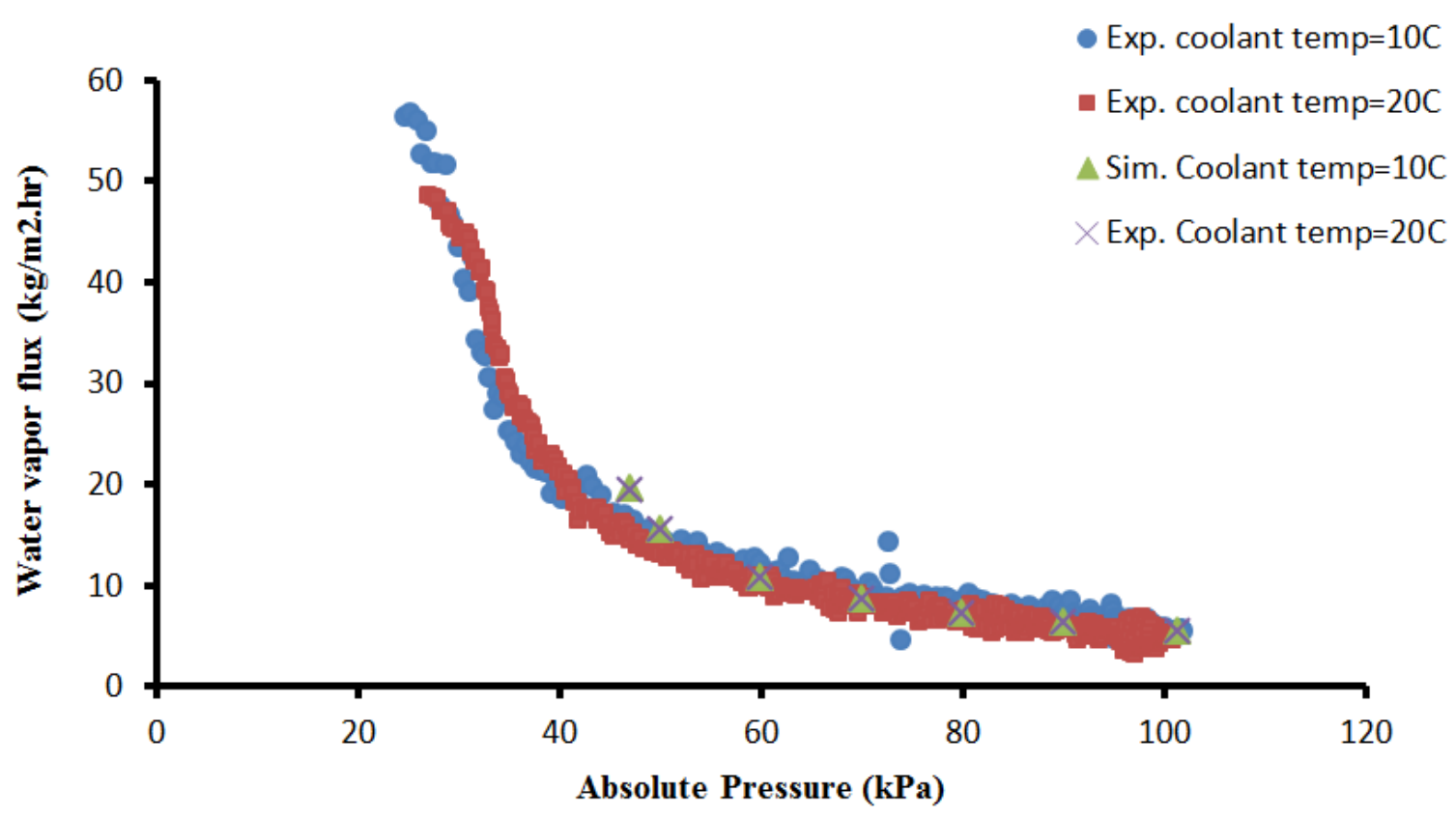

Figure 11: Simulated and experimental tests $v s$ absolute pressure for two different coolant temperatures $\left(\mathrm{T}_{\mathrm{f}}=80^{\circ} \mathrm{C}\right)$. 


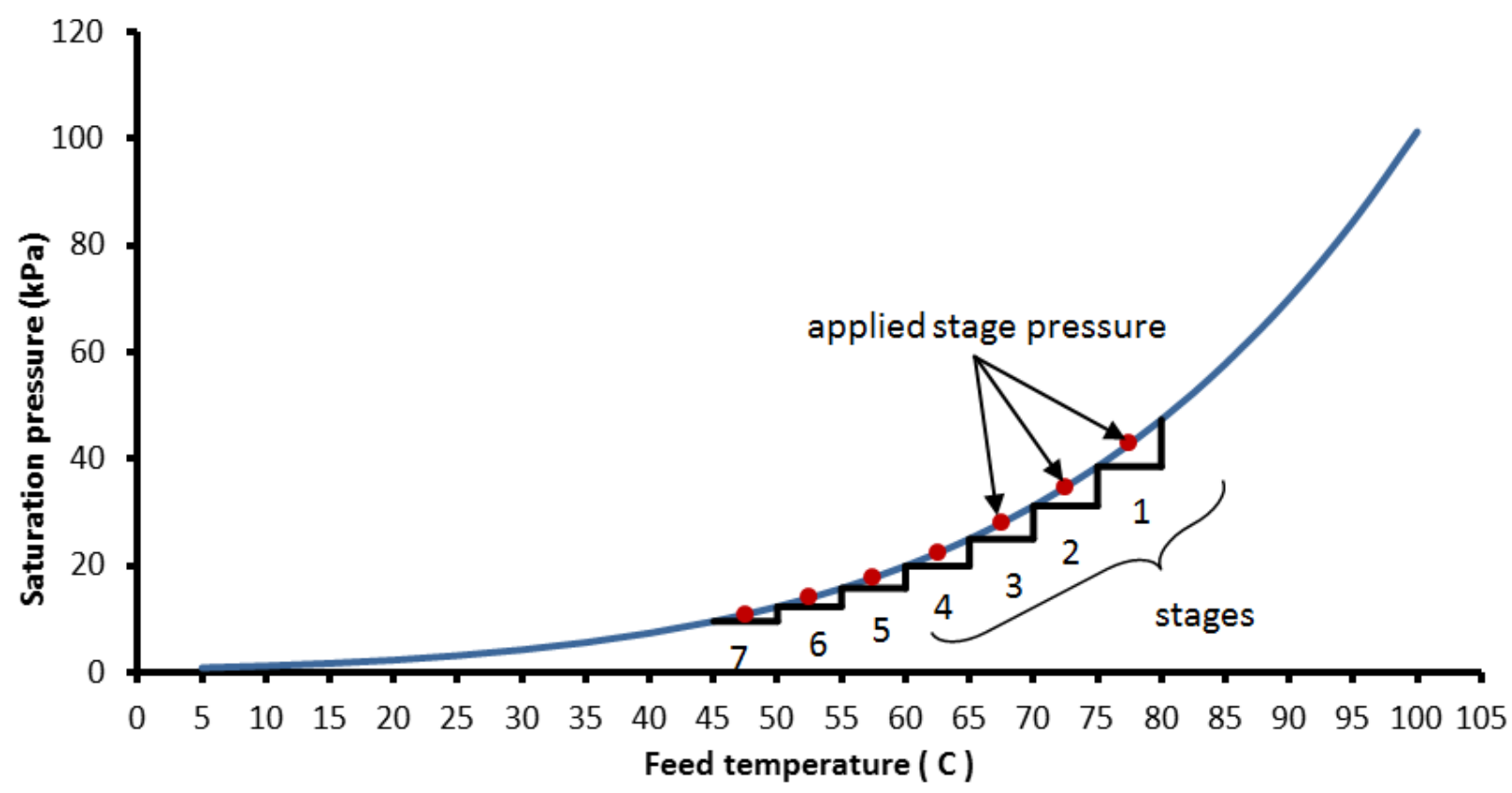

Figure 12: Maintaining the evaporating medium condition at the vapor pressure -temperature equilibrium curve through staging. 
No. of Stages $=1$

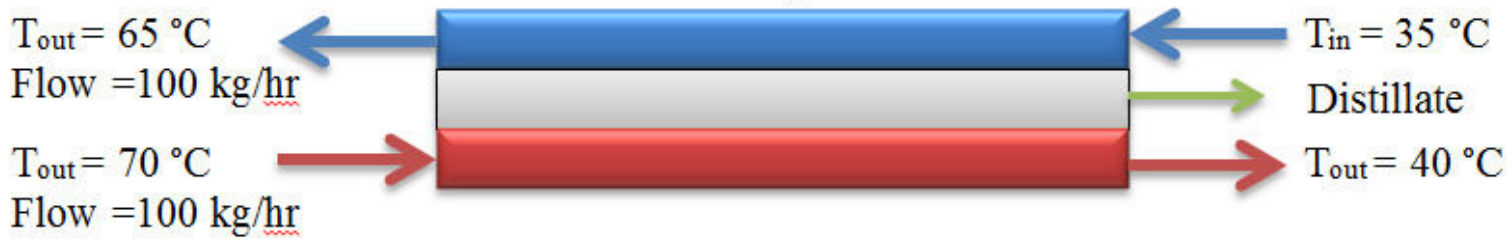

No. of Stages $=2$

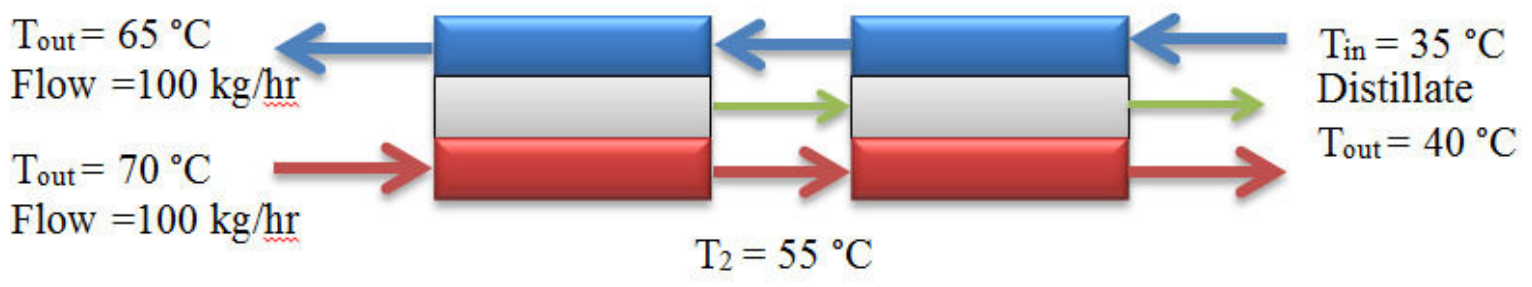

No. of Stages $=3$

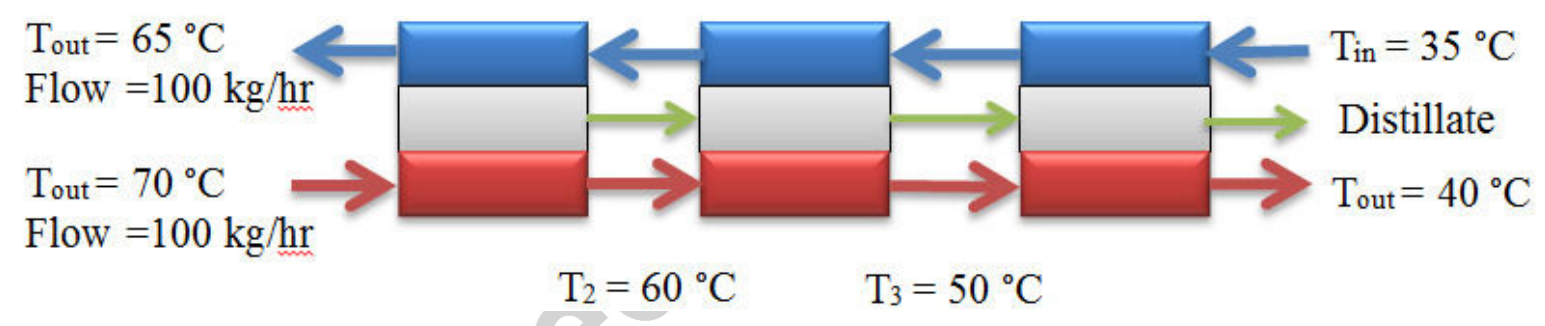

Figure 13: Illustration of sub-atmospheric AGMD staging. 


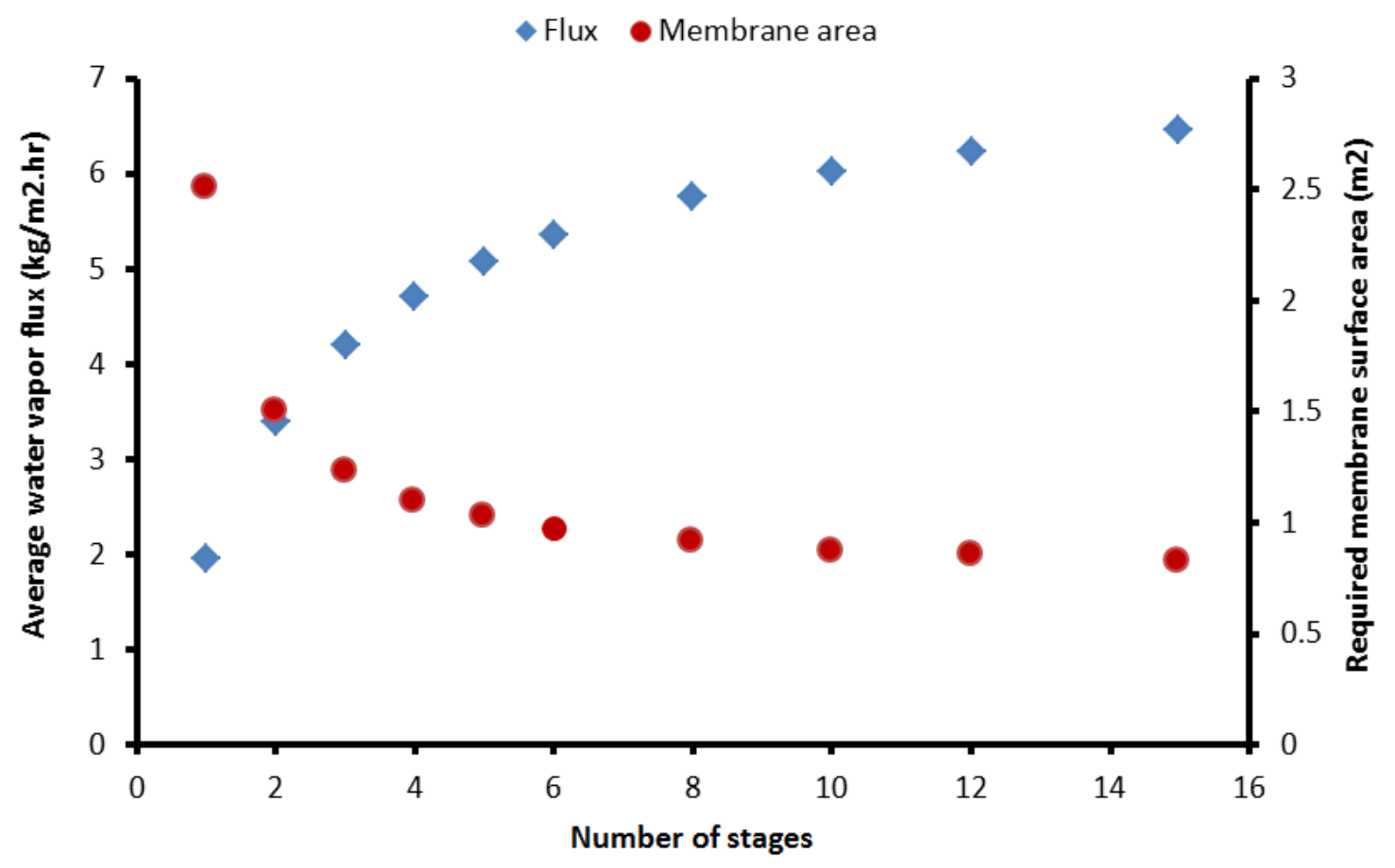

Figure 14: Simulating the staging effect of sub-atmospheric AGMD on the flux and the required membrane area (producing the same capacity). 


\section{Highlights}

- The effect of non-condensable gases on flux in sub-atmospheric AGMD is studied

- Removing non-condensable gases increased the flux by more than three-fold

- The gap width becomes less important at the absence of non-condensable gases

- The importance of staging the sub-atmospheric AGMD process is also highlighted

- The simulated predictions were found to be strongly correlated with the experimental data 